\title{
Supporting Information: Tuning the Elasticity of Cross-Linked Gold Nanoparticle Assemblies
}

Hendrik Schlicke, ${ }^{\dagger,}, \#$ Svenja Kunze, ${ }^{\dagger, \#}$ Maik Finsel, ${ }^{\dagger}$ Elisabeth W. Leib, ${ }^{\dagger,}$

Clemens J. Schröter, ${ }^{\dagger}$ Malte Blankenburg, ${ }^{\S}$ Heshmat Noei, $\|, \perp$ and Tobias Vossmeyer ${ }^{*, \dagger}$

$\dagger$ Institute of Physical Chemistry, University of Hamburg, Grindelallee 117, 20146 Hamburg, Germany

$\ddagger$ Present Address: Fraunhofer Center for Applied Nanotechnology CAN, Grindelallee 117, 20146 Hamburg, Germany

TPresent address: Wacker Chemie AG, Johannes-Hess-Straße 24, 84489 Burghausen, Germany

§Helmholtz-Zentrum Geesthacht, Max-Planck-Straße 1, 21502 Geesthacht, Germany

||Deutsches Elektronen-Synchrotron (DESY), D-22607 Hamburg, Germany

$\perp$ Physics Department, University of Hamburg, 20355 Hamburg, Germany. \#Contributed equally to this work.

E-mail: tobias.vossmeyer@chemie.uni-hamburg.de 


\section{S1 Gold Nanoparticles}

Gold nanoparticles (GNPs) capped with 1-dodecylamine (12A) were synthesized as described by Leff et al.. ${ }^{1}$ Figure S1 shows UV/vis absorbance spectra of the diluted GNP batches 1-6 used for the fabrication of cross-linked GNP films. The spectra show the typical surface plasmon resonance peak at $504-513 \mathrm{~nm}$ (Table $\mathrm{S} 1$ ).

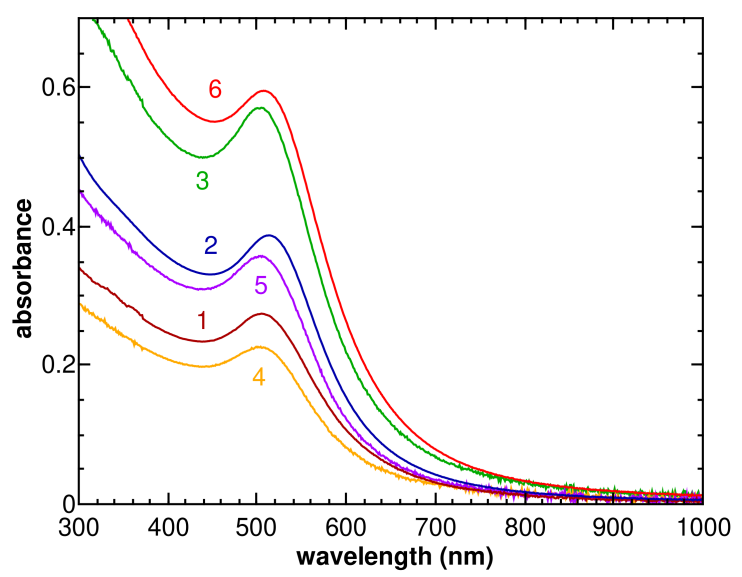

Figure S1: UV/vis absorbance spectra (dilution factor $f=1 / 600(1-5)$ as well as $f=1 / 300$ (6), path length $d=10 \mathrm{~mm}$ ) of the GNP batches 1-6 utilized in this study.

For the determination of the GNP sizes, transmission electron microscopy (TEM) was conducted using a JEOL JEM-1011 microscope, equipped with a $\mathrm{LaB}_{6}$ cathode and operated at $100 \mathrm{kV}$. Prior to TEM analysis the 12A ligands on the GNP surface were exchanged by 1-dodecanethiol (12T) or 1-hexadecanethiol (16T) to improve the particle stability under TEM conditions. ${ }^{2}$ Figure S2 depicts representative transmission electron micrographs and corresponding size histograms of the GNP batches 1-6. The average particle diameters were determined by taking into account the projected areas of the particles and are listed in table S1. Particles with diameters $<1 \mathrm{~nm}$ were excluded from sizing statistics. 

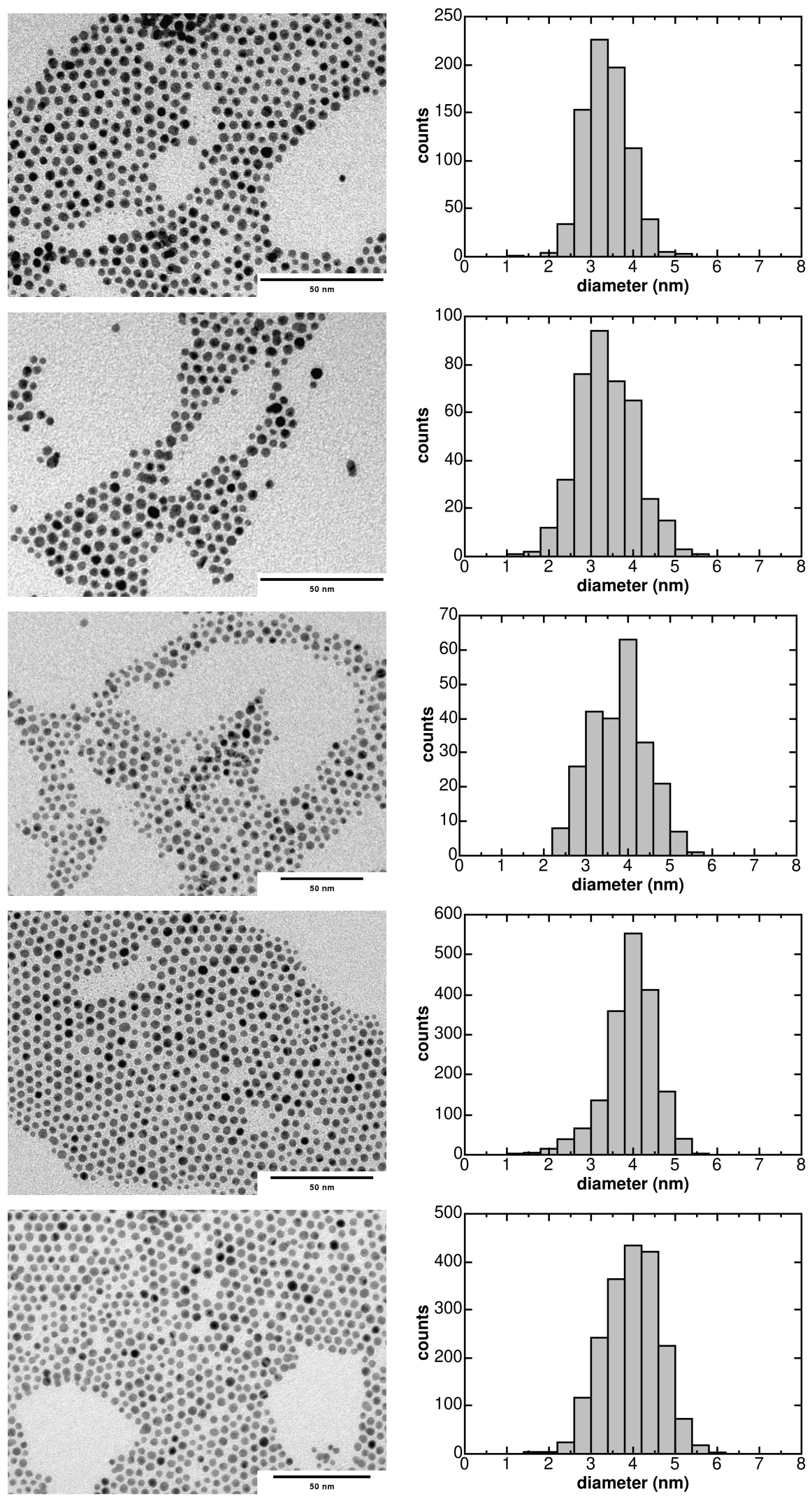

Figure S2: Transmission electron micrographs (left) and corresponding size histograms (right) for GNP batches 1-5 (from top to bottom). 

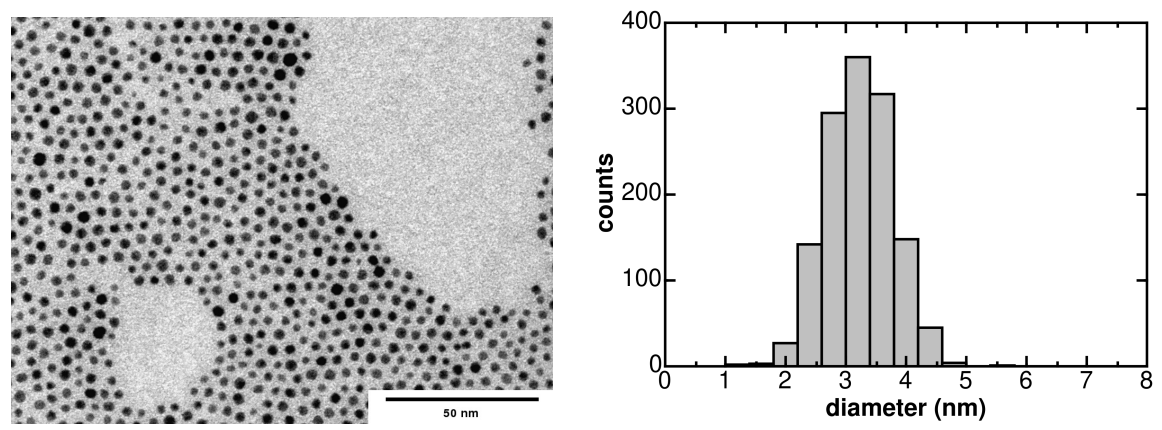

Figure S2: Transmission electron micrograph (left) and corresponding size histogram (right) for GNP batch 6 .

Table S1: Average particle diameters and SPR wavelengths of GNP batches 1-6.

\begin{tabular}{ccc}
\hline GNP batch & $\begin{array}{c}\text { diameter } \\
d / \mathrm{nm}\end{array}$ & $\begin{array}{c}\text { sPavelength } \\
\lambda_{\text {SPR }} / \mathrm{nm}\end{array}$ \\
\hline GNP1 & $3.4 \pm 0.5$ & 505 \\
GNP2 & $3.4 \pm 0.7$ & 513 \\
GNP3 & $3.8 \pm 0.7$ & 507 \\
GNP4 & $3.9 \pm 0.6$ & 504 \\
GNP5 & $4.0 \pm 0.7$ & 507 \\
GNP6 & $3.2 \pm 0.5$ & 507 \\
\hline
\end{tabular}




\section{S2 Film Thickness Measurements}

GNP film thickness measurements were performed by scratching trenches into the as-deposited samples on glass substrates using a scalpel or cannula. For each sample at least two different locations at the film edges were chosen and atomic force microscope (AFM) scans $\left(20 \times 1.25 \mathrm{um}^{2}, 512 \times 32 \mathrm{px}^{2}\right)$ were conducted using a JPK Nanowizard AFM or a DI Multimode AFM (100 um scanner, Nanoscope IV controller). For every AFM scan, at least three step-profiles were generated and the obtained step-height values were averaged.

Figure S3 shows three exemplary AFM scans of GNP film sample 08DT-1 (see Table S4). From the extracted height profiles of this sample an average thickness of $(33 \pm 1)$ nm was determined.
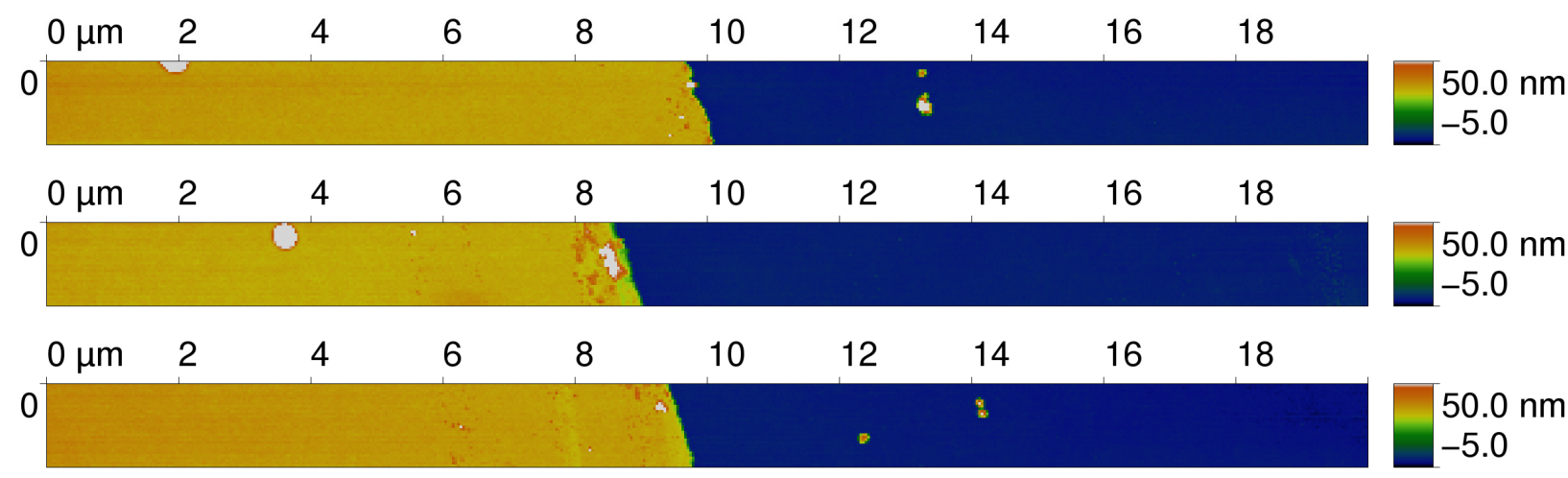

Figure S3: AFM scans $\left(20 \times 1.25 \mu^{2}\right)$ of three different GNP film sections used for thickness measurements of sample 08DT-1. 


\section{S3 X-ray Diffraction Measurements}

Figure S4 shows x-ray diffractograms of GNP films cross-linked with different $\alpha, \omega$-alkanedithiols (ADTs) and 1,4-benzenedithiol (BDT), as well as of a reference sample obtained by dropcasting the 12A-stabilized GNP stock solution. The green solid lines depict lorentzians fitted to the gold (220) reflections in the interval between $58^{\circ}$ and $72^{\circ}$. Table S2 denotes the full width at half maximum (FWHM) $w$ extracted from the fits, the peak center $2 \theta_{0}$, and the coherent crystalline domain size $L$ calculated using the Scherrer equation 1. A shape factor of $K=1$ was assumed.

$$
L=\frac{K \lambda}{w \cos \theta_{0}}
$$

Table S2: FWHM $w$ and peak center $2 \theta_{0}$ extracted from fits of lorentzians to the gold (220) reflections, and crystalline domain size $L$ calculated using the Scherrer equation 1.

\begin{tabular}{lccc}
\hline sample & $w /{ }^{\circ}$ & $2 \theta_{0} /^{\circ}$ & $L / \mathrm{nm}$ \\
\hline BDT & 3.30 & 64.74 & 3.16 \\
\hline 4DT & 3.59 & 64.80 & 2.91 \\
5DT & 3.34 & 64.91 & 3.13 \\
6DT & 3.73 & 64.67 & 2.80 \\
8DT & 3.35 & 64.79 & 3.12 \\
9DT & 3.87 & 64.69 & 2.70 \\
10DT & 3.43 & 64.72 & 3.04 \\
\hline GNP & 3.74 & 64.80 & 2.79 \\
\hline
\end{tabular}




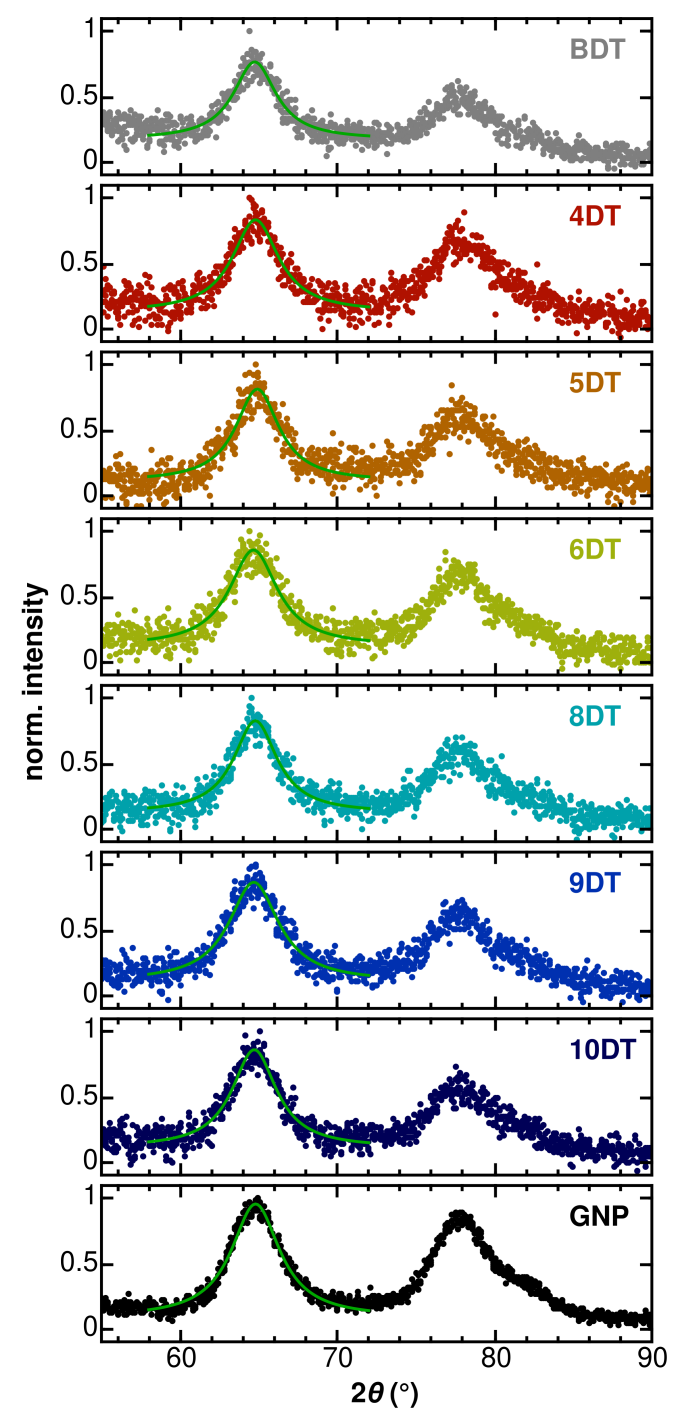

Figure S4: X-ray diffractograms of GNP film samples cross-linked with different ADTs and BDT, as indicated. For reference, a diffractogram of a drop-cast sample from a 12A-stabilized GNP stock solution is provided (GNP). 


\section{S4 Charge Transport Measurements}

Charge transport measurements at cryogenic temperatures were conducted to determine the

charge transport activation energies according to an Arrhenius activation model (equation $2) .^{3}$

$$
\sigma=\sigma_{0} \exp \left(-\frac{E_{\mathrm{A}}}{k T}\right)
$$

Here, $\sigma$ denotes the conductivity, $\sigma_{0}$ a preexponential factor, $E_{\mathrm{A}}$ the activation energy, $k$ the Boltzmann constant and $T$ the temperature. Figure S5 depicts Arrhenius plots of the conductivities of GNP films cross-linked using different ADTs and BDT. Linear fits to the data were used to extract the charge transport activation energies. These are denoted in table S3 togehter with the film conductivities measured at $300 \mathrm{~K}$.

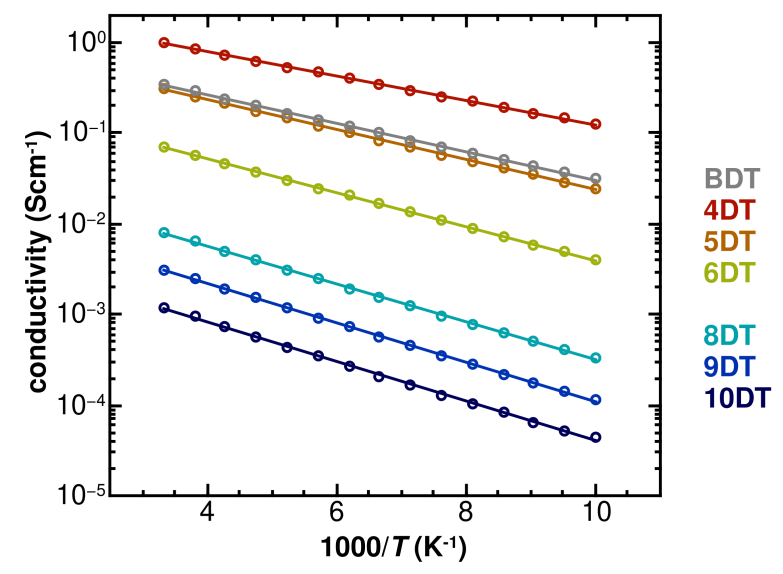

Figure S5: Conductivities $\sigma$ of the cross-linked GNP films as a function of $T^{-1}$. Solid lines represent linear fits according to Arrhenius activation. 
Table S3: Conductivities measured at $300 \mathrm{~K}$ and charge transport activation energies computed from temperature-dependent conductivity measurements in a range from 100 to $300 \mathrm{~K}$.

\begin{tabular}{ccc}
\hline ADT linker & $\begin{array}{c}\text { Conductivity } \\
\sigma_{300 \mathrm{~K}} / \mathrm{Scm}^{-1}\end{array}$ & $\begin{array}{c}\text { Activation energy } \\
E_{\mathrm{A}} / \mathrm{meV}\end{array}$ \\
\hline 4DT & 1.0 & 27 \\
5DT & $3.1 \cdot 10^{-1}$ & 33 \\
6DT & $7.1 \cdot 10^{-2}$ & 37 \\
8DT & $8.0 \cdot 10^{-3}$ & 41 \\
9DT & $3.2 \cdot 10^{-3}$ & 43 \\
10DT & $1.2 \cdot 10^{-3}$ & 43 \\
\hline BDT & $3.4 \cdot 10^{-1}$ & 31 \\
\hline
\end{tabular}




\section{S5 X-ray Photoelectron Spectroscopy (XPS)}

To investigate the composition of ADT cross-linked GNP films XPS measurements were conducted. Figure S6a shows XPS spectra corresponding to the C 1s energy range. The signals were fitted using 3 (4DT, 6DT) or 2 gaussians, corresponding to sulfur-bound carbon (through grey lines), carbon-bound carbon (dashed lines) and oxidized carbon species (dotted grey lines). The latter are attributed to traces of contaminants as, e.g., residual solvent. The dotted black lines represent the background signal.

Figure S6b shows XPS spectra corresponding to the Au 4f energy range. The signals were fitted using 4 gaussians (through grey lines). Here, the dotted black lines again represent the background signal.
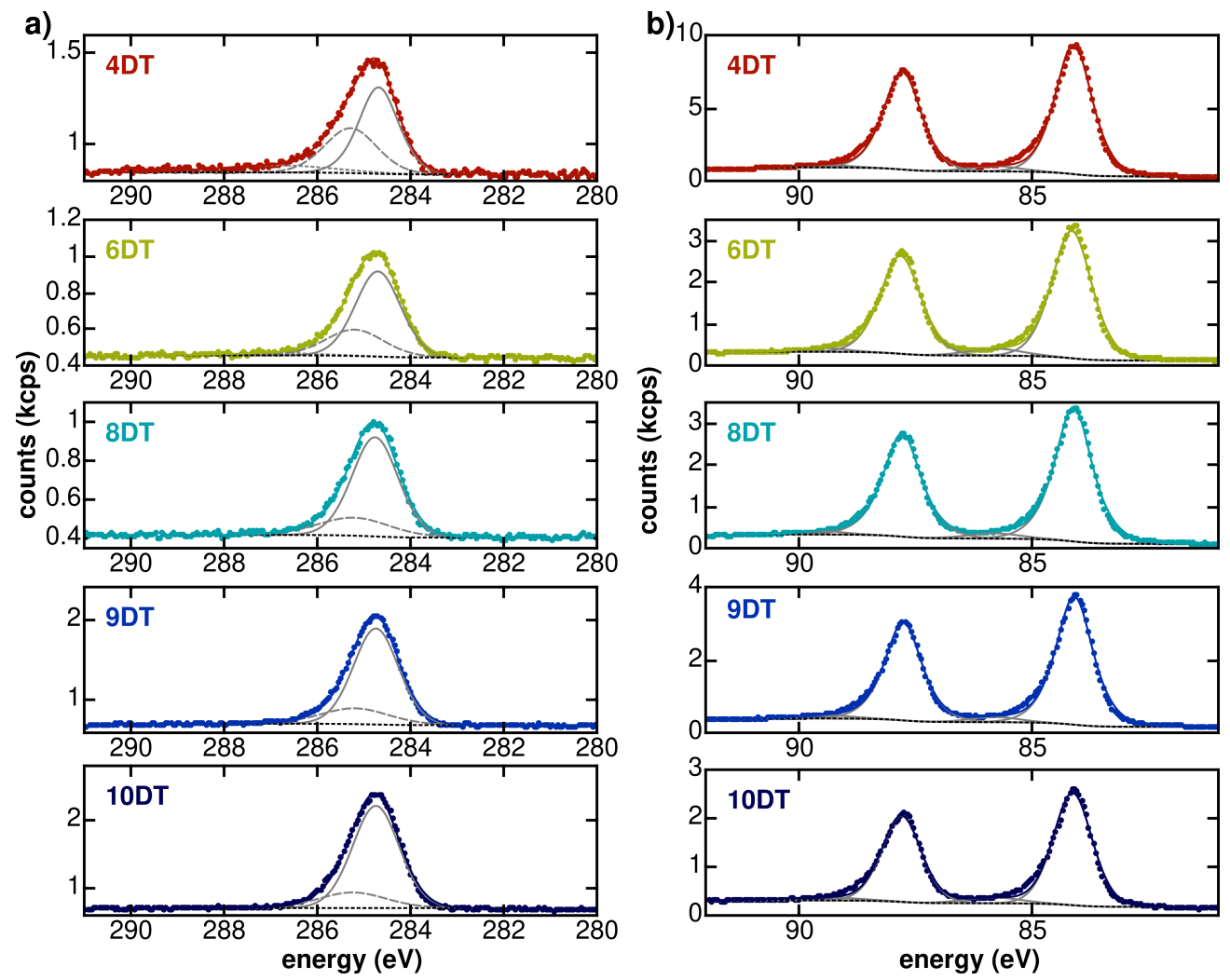

Figure S6: XPS spectra of the a) C 1s and b) Au 4f energy regions.

Figure S7a depicts the $\mathrm{N}$ 1s core level region of a survey scan. Here, for all investigated GNP films cross-linked with different ADTs, as indicated, no signals were observed in the 

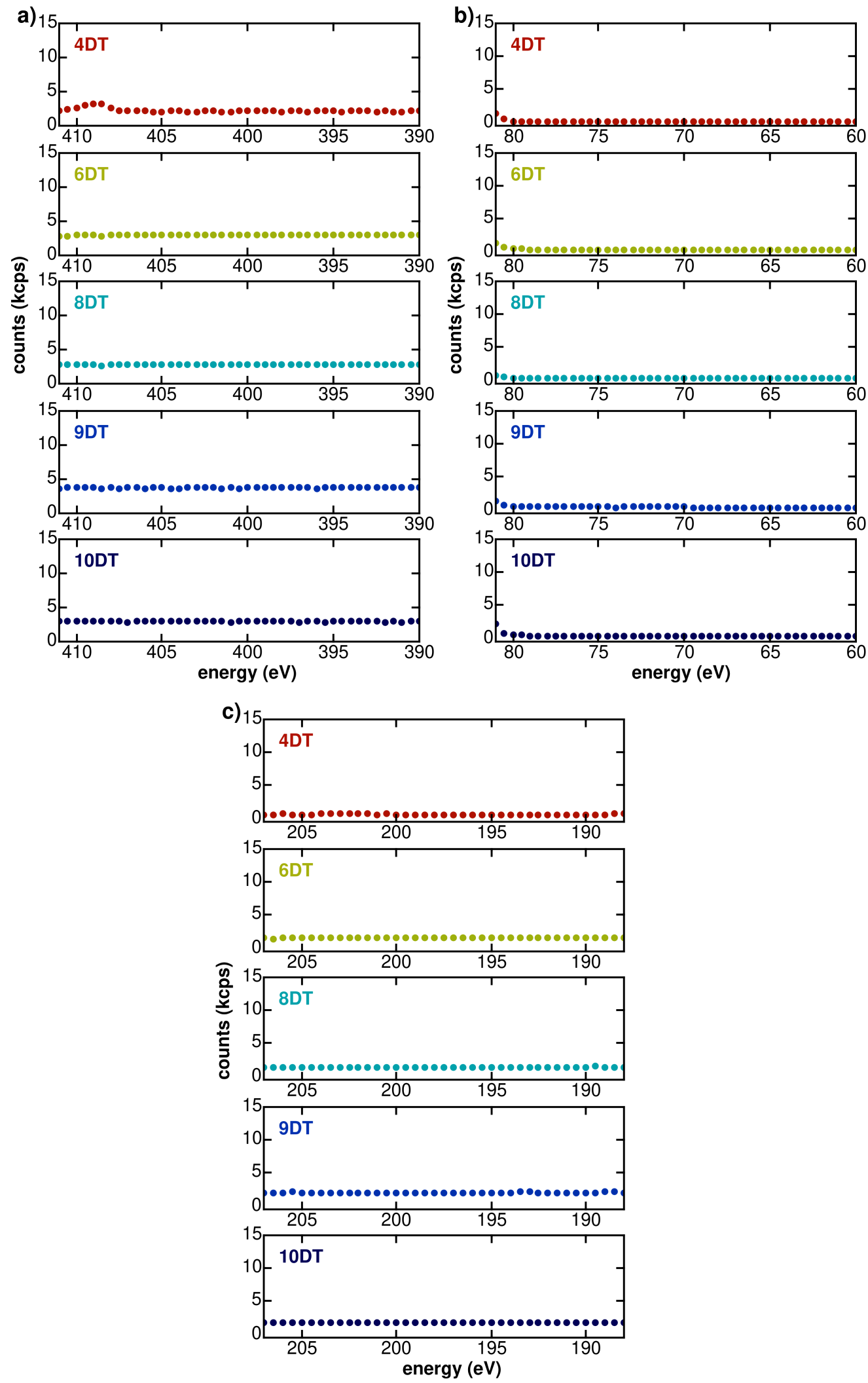

Figure S7: XPS survey spectra of the energy regions corresponding to a) N 1s, b) Br 3d and c) $\mathrm{Cl} 2 \mathrm{p}$. 
energy range between 398 and $400 \mathrm{eV}$, confirming that the original 1-dodecylamine ligands were successfully exchanged by ADT cross-linkers. Further, no signals were observed at energies around $70 \mathrm{eV}$ for $\mathrm{Br} 3 \mathrm{~d}$ (figure $\mathrm{S} 7 \mathrm{~b}$ ) and around $198 \mathrm{eV}$ for $\mathrm{Cl} 2 \mathrm{p}$ (figure $\mathrm{S} 7 \mathrm{c}$ ). These results confirm that also reaction precursors (tetrachloroauric acid, tetraoctylammonium bromide) were not present in the final GNP films. 


\section{S6 Transmission Electron Microscopy}

Figure S8 depicts transmission electron micrographs of GNP films cross-linked with different ADTs and BDT, as indicated. The films were transferred onto carbon-coated TEM substrates for investigation. Transmission electron micrographs were acquired using a JEOL JEM-1011 machine, equipped with a $\mathrm{LaB}_{6}$ cathode and operated at $100 \mathrm{kV}$. 

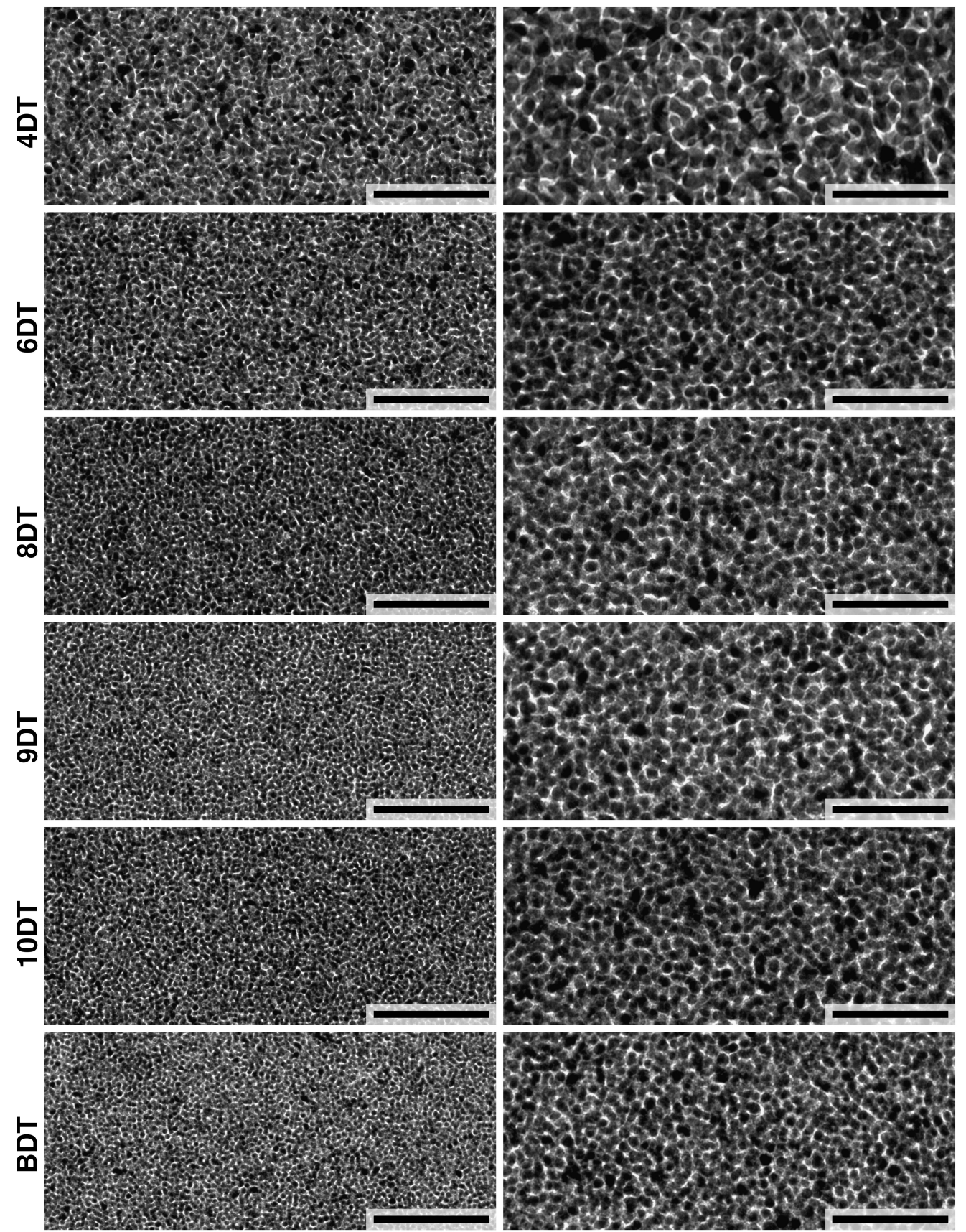

Figure S8: Transmission electron micrographs of GNP films cross-linked using different ADTs and BDT, as indicated. Scale bars: $100 \mathrm{~nm}$ (left), $50 \mathrm{~nm}$ (right). 


\section{S7 Small Angle X-ray Scattering}

Figure S9 depicts small angle x-ray scattering curves recorded for GNP films cross-linked using different ADTs and BDT. The black lines depict fits of an fcc structural model using the software scatter. ${ }^{4}$
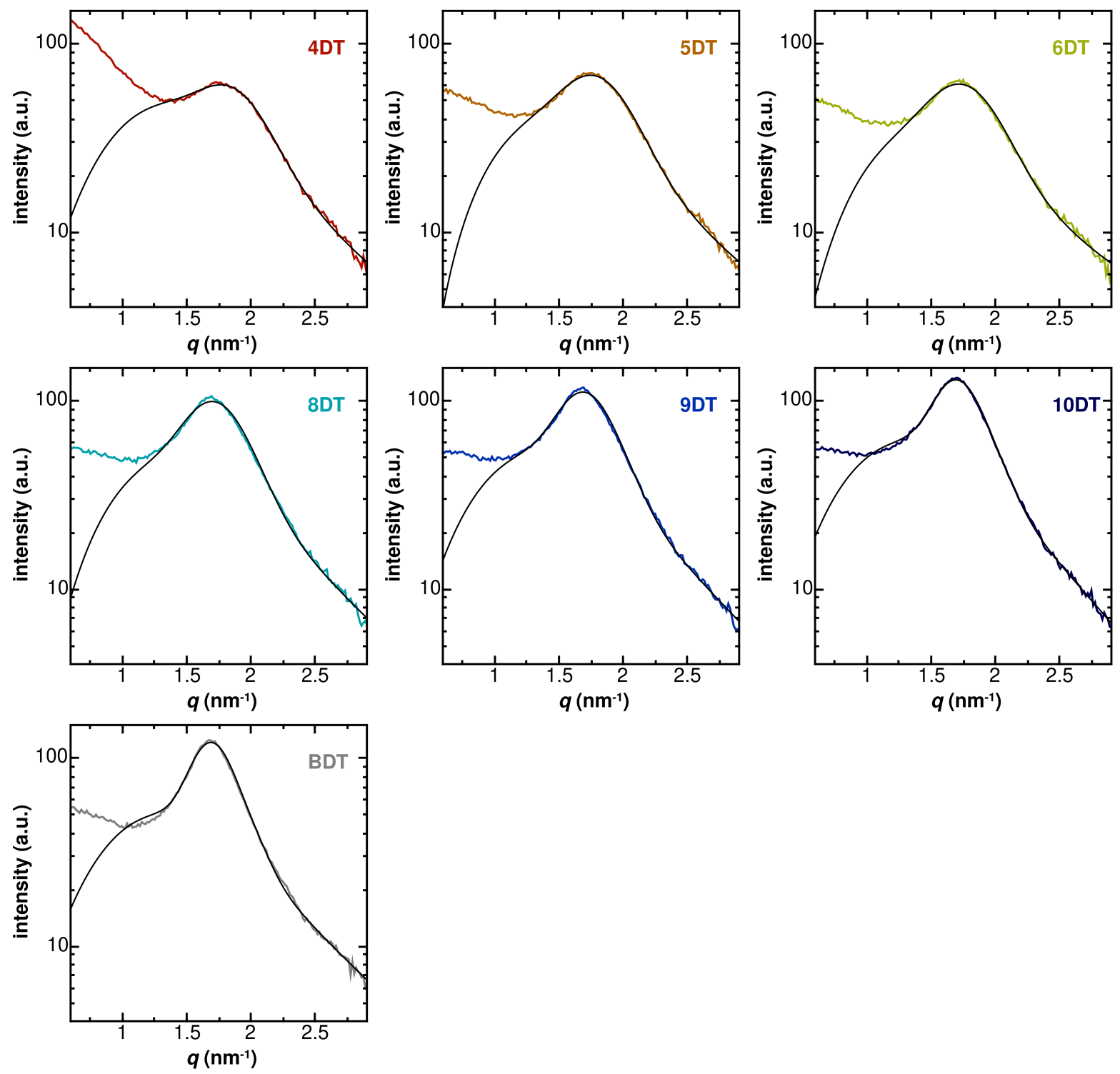

Figure S9: Small angle x-ray scattering curves recorded for GNP films cross-linked using different ADTs and BDT, as indicated. The black lines depict fits of an fcc structural model. 


\section{S8 Additional Data for Bulge Tests}

Table S4 lists all GNP membrane samples investigated regarding their mechanical properties with their membrane thickness $t_{\mathrm{m}}$, the biaxial moduli extracted from stress-strain data obtained at ascending as well as descending pressures $Y_{\text {asc }}$ and $Y_{\text {desc }}$, respectively, as well as the membrane pre-stress values $\sigma_{0, \text { asc }}$ and $\sigma_{0, \text { desc }}$.

Beginning on page S-18 optical micrographs and topographic AFM full scans of each sample are provided. Further, the pressure dependent bulge radii of curvature and extracted stress-strain data are given. The blue and red triangles denote data points collected at ascending and decreasing pressures, respectively. 
Table S4: Listing of all GNP membrane samples investigated using bulge tests. The table denotes the GNP batch used for membrane fabrication, the membrane thickness $t_{\mathrm{m}}$, the biaxial moduli extracted from stress-strain data obtained at ascending as well as descending pressures $Y_{\text {asc }}$ and $Y_{\text {desc }}$, respectively, as well as the membrane pre-stress $\sigma_{0 \text {,asc }}$ and $\sigma_{0 \text {,desc }}$.

\begin{tabular}{lcccccc}
\hline sample & GNP batch & $\begin{array}{c}t_{\mathrm{m}} \\
/ \mathrm{nm}\end{array}$ & $\begin{array}{c}Y_{\text {asc }} \\
/ \mathrm{GPa}\end{array}$ & $\begin{array}{c}Y_{\text {desc }} \\
/ \mathrm{GPa}\end{array}$ & $\begin{array}{c}\sigma_{0, \text { asc }} \\
/ \mathrm{MPa}\end{array}$ & $\begin{array}{c}\sigma_{0, \text { desc }} \\
/ \mathrm{MPa}\end{array}$ \\
\hline 03DT-1A & 2 & 34.4 & 13.2 & 13.0 & 16.2 & 15.9 \\
03DT-1B & 2 & 34.4 & 16.1 & 16.9 & 22.2 & 21.5 \\
\hline 04DT-1 & 2 & 24.3 & 17.5 & 18.7 & 24.7 & 24.2 \\
04DT-2A & 2 & 34.2 & 12.8 & 13.4 & 15.8 & 15.4 \\
04DT-2B & 2 & 34.2 & 15.7 & 16.0 & 4.5 & 3.4 \\
04DT-3 & 1 & 36.3 & 15.2 & 13.8 & 14.6 & 14.7 \\
\hline 05DT-1 & 2 & 37.2 & 9.9 & 10.2 & 7.5 & 7.0 \\
05DT-2 & 4 & 31.1 & 10.7 & & 6.7 & \\
\hline 06DT-1 & 2 & 40.5 & 9.7 & 11.0 & -7.8 & -10.5 \\
06DT-2A & 2 & 38.7 & 8.6 & 9.3 & 8.7 & 7.8 \\
06DT-2B & 2 & 38.7 & 8.9 & 9.7 & 3.6 & 2.2 \\
06DT-2C & 2 & 38.7 & 8.4 & 9.2 & -9.0 & -10.9 \\
06DT-3 & 4 & 24.0 & 7.8 & 8.7 & 6.9 & 5.0 \\
06DT-4 & 4 & 24.0 & 6.2 & 6.0 & 9.8 & 9.4 \\
\hline 08DT-1 & 2 & 32.9 & 4.2 & 4.9 & -2.9 & -5.3 \\
08DT-2A & 1 & 43.3 & 6.2 & 7.3 & 1.8 & 0.1 \\
08DT-2B & 1 & 43.3 & 5.8 & 6.8 & -1.8 & -4.1 \\
08DT-3 & 2 & 44.1 & 5.6 & 5.8 & -5.1 & -6.0 \\
08DT-4 & 3 & 44.1 & 5.2 & 5.9 & -2.8 & -4.8 \\
\hline 09DT-1 & 2 & 47.6 & 4.6 & 4.9 & 2.3 & 1.6 \\
09DT-2A & 2 & 47.7 & 5.5 & 6.2 & 2.6 & 1.4 \\
09DT-2B & 2 & 47.7 & 7.7 & 8.8 & -6.8 & -9.1 \\
09DT-2C & 2 & 47.7 & 4.9 & 5.1 & 2.8 & 2.3 \\
09DT-3 & 5 & 34.2 & 4.2 & 5.1 & 6.2 & 4.4 \\
\hline 10DT-1 & 2 & 40.4 & 4.8 & 5.8 & 1.3 & -1.0 \\
10DT-2A & 1 & 51.3 & 5.0 & 5.5 & -3.8 & -5.2 \\
10DT-2B & 1 & 51.3 & 4.8 & 5.4 & 1.4 & 0.1 \\
10DT-3A & 3 & 46.8 & 4.6 & 6.3 & -3.4 & -7.7 \\
10DT-3B & 3 & 46.8 & 5.3 & 5.7 & -3.3 & -4.4 \\
10DT-3C & 3 & 46.8 & 4.6 & 6.1 & 4.4 & 2.3 \\
\hline BDT-1 & 4 & 21.0 & 12.3 & 13.8 & 4.8 & 1.8 \\
BDT-2 & 3 & 43.4 & 13.4 & 14.6 & 16.5 & 16.0 \\
\hline
\end{tabular}




\section{S8.1 3DT Cross-Linked Samples}
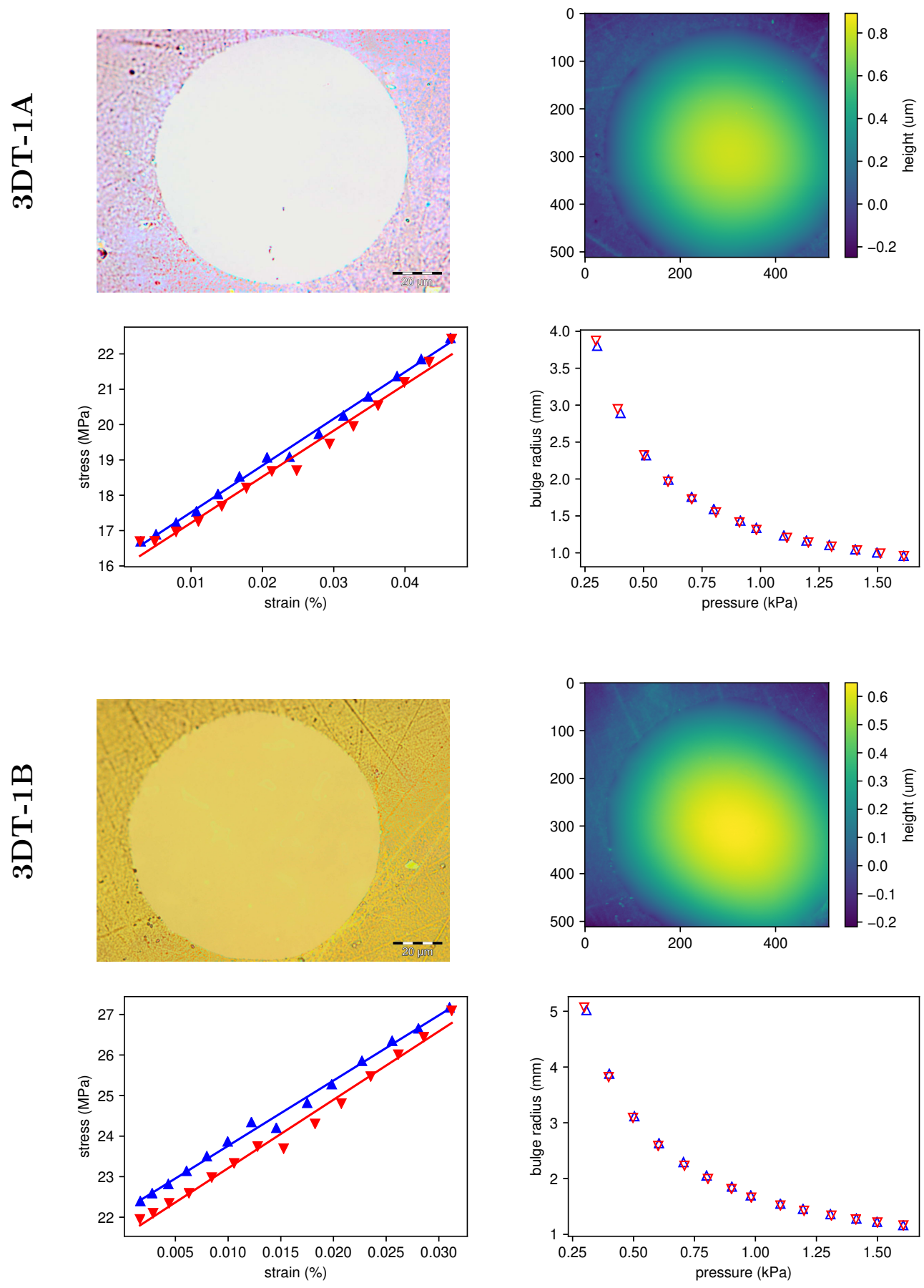


\section{S8.2 4DT Cross-Linked Samples}
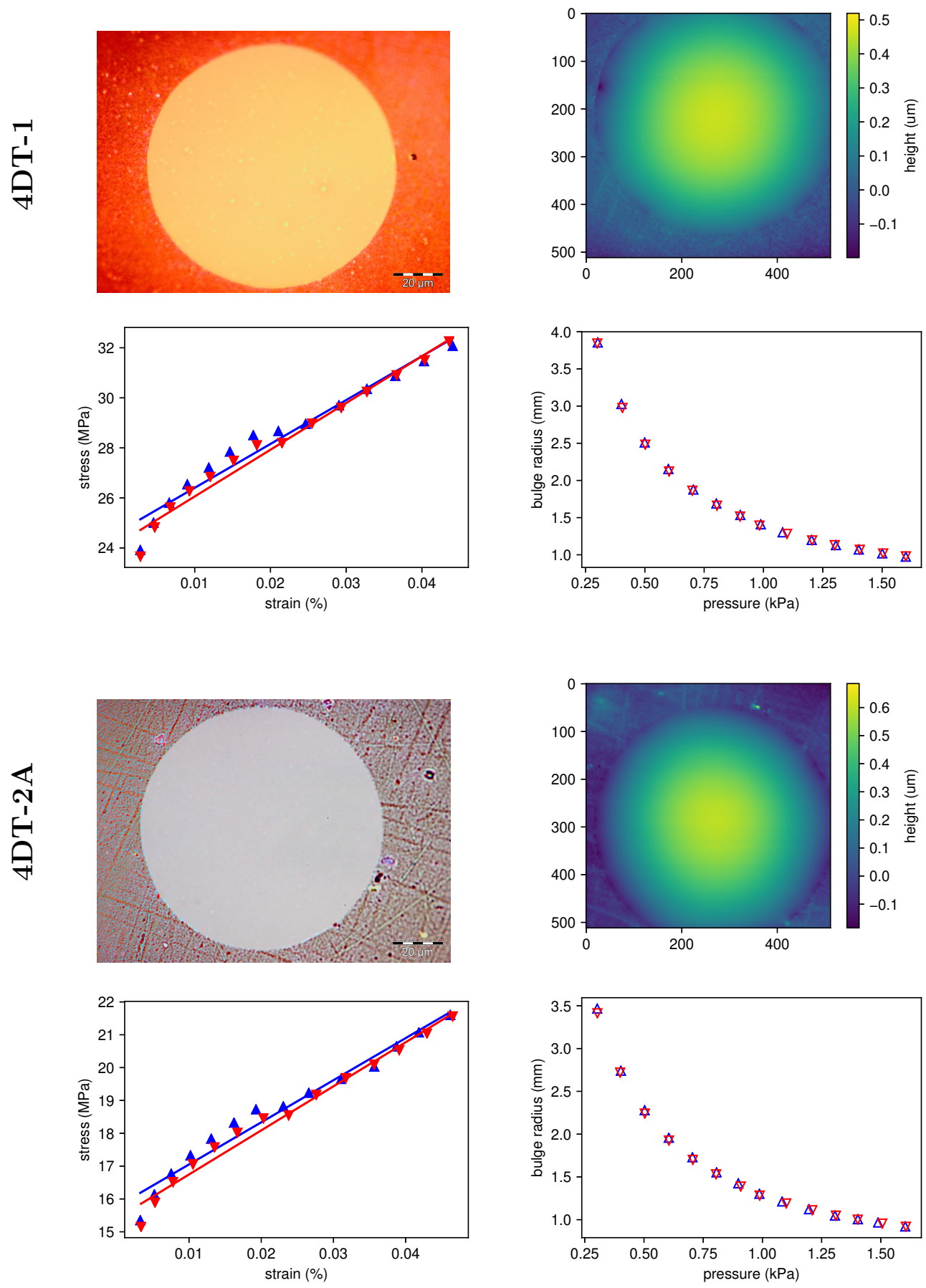

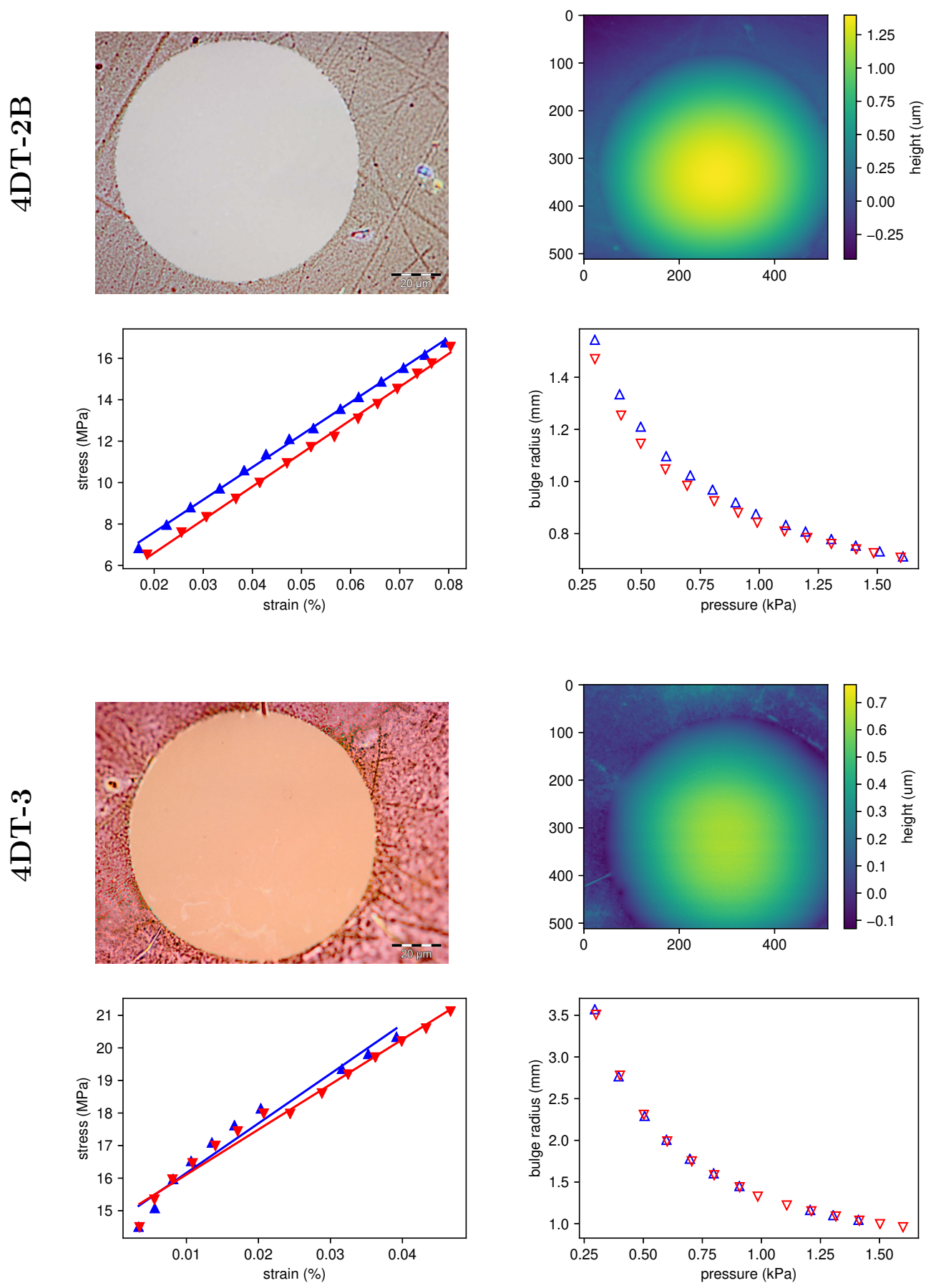


\section{S8.3 5DT Cross-Linked Samples}
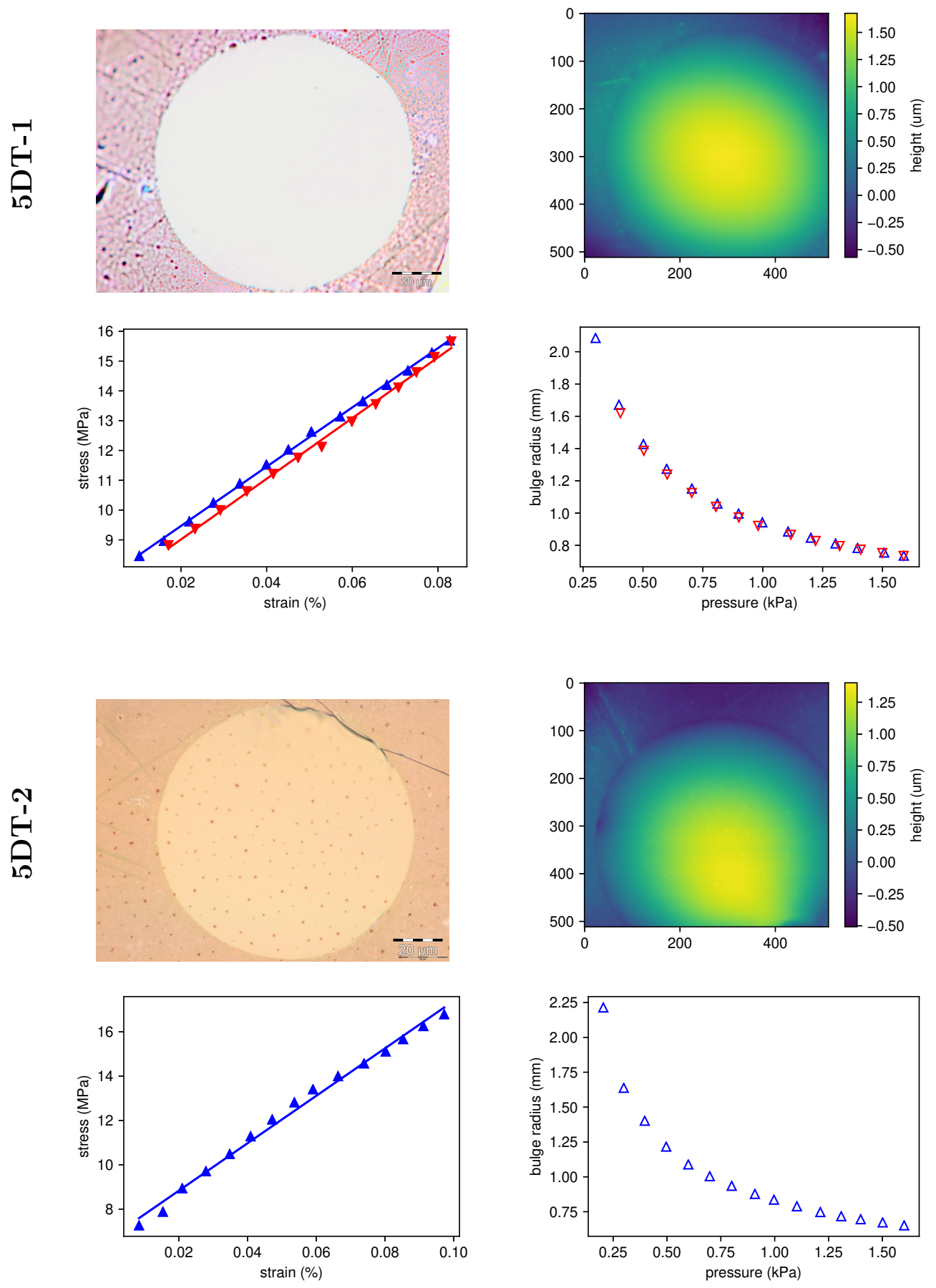


\section{S8.4 6DT Cross-Linked Samples}
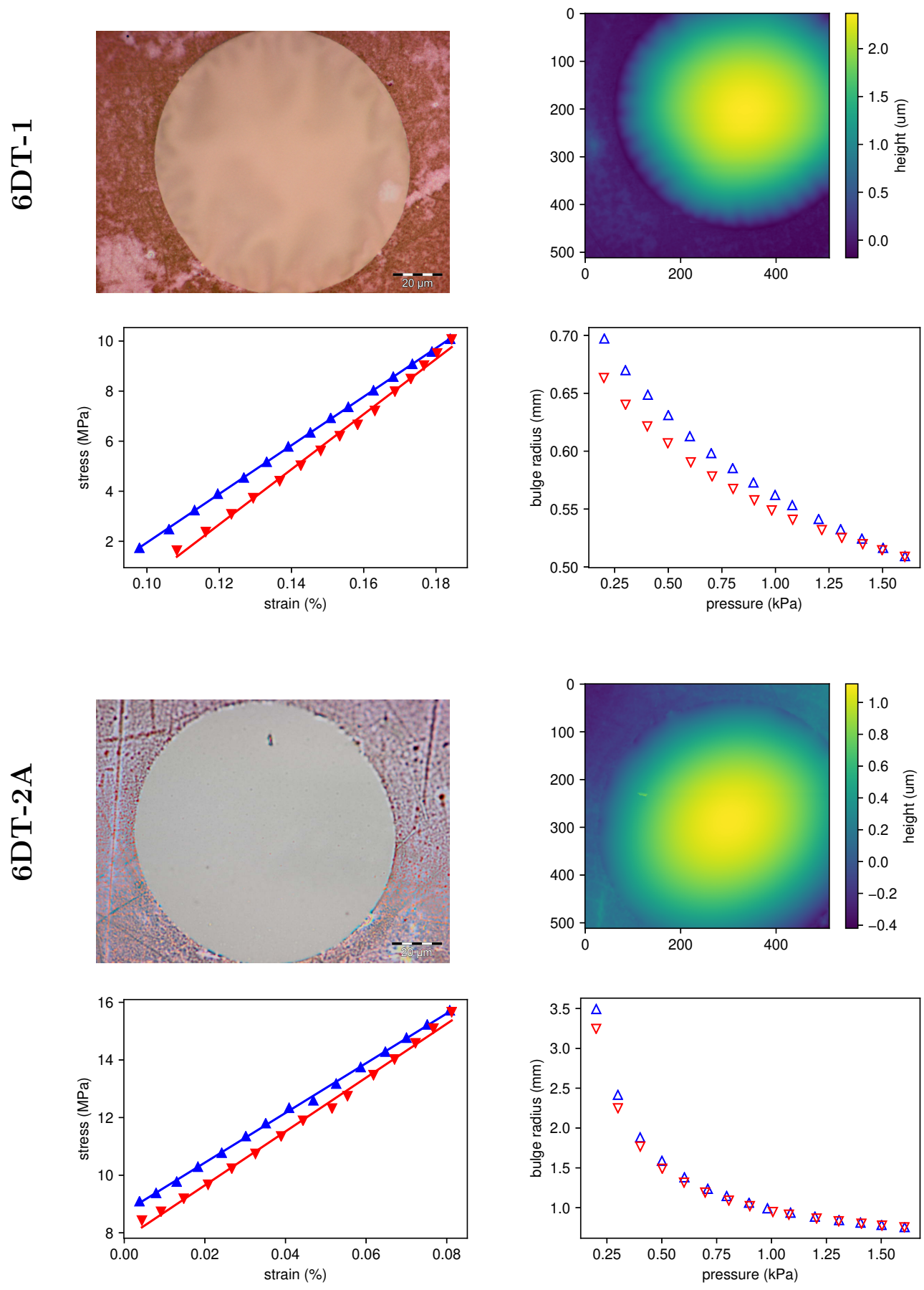

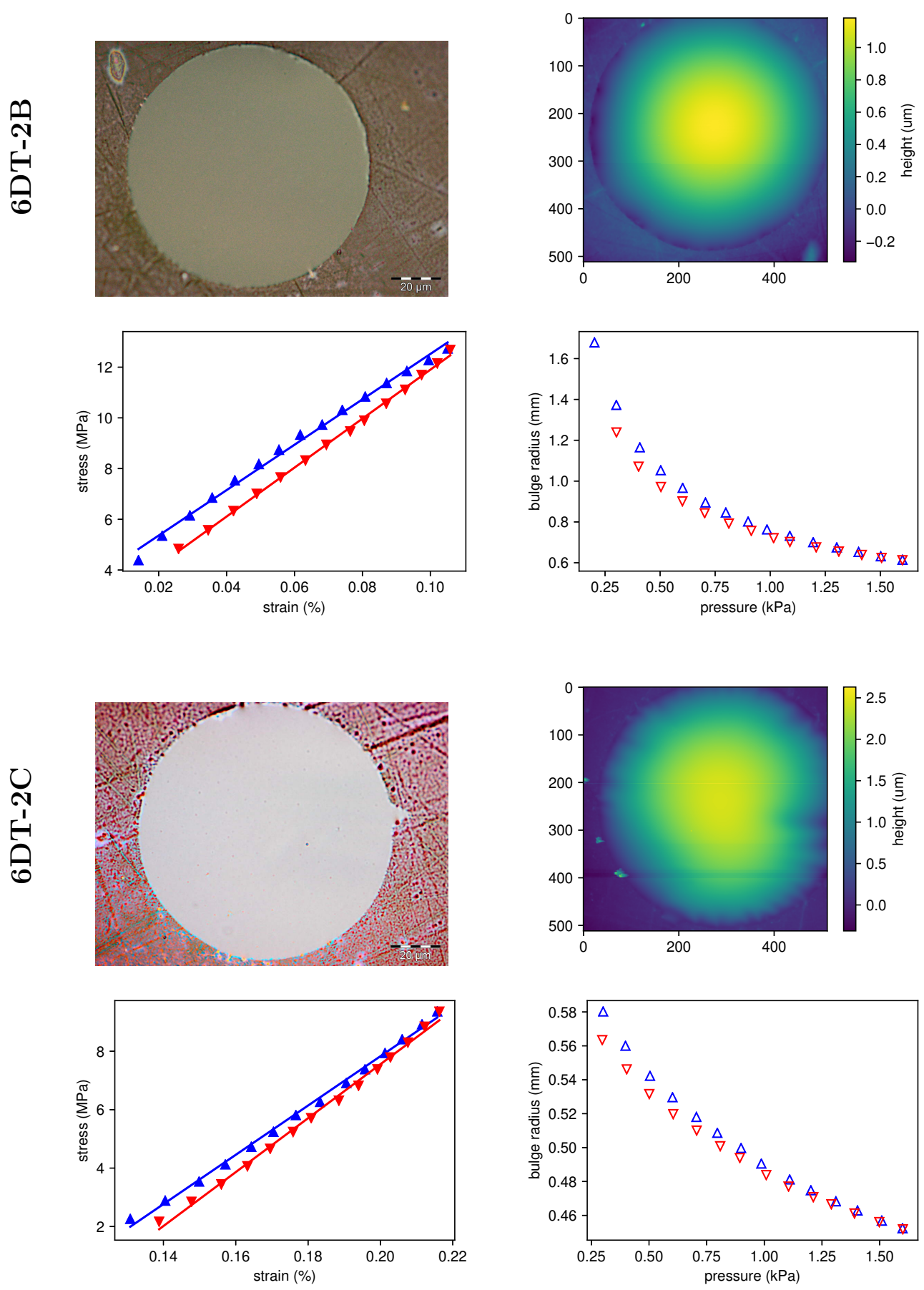

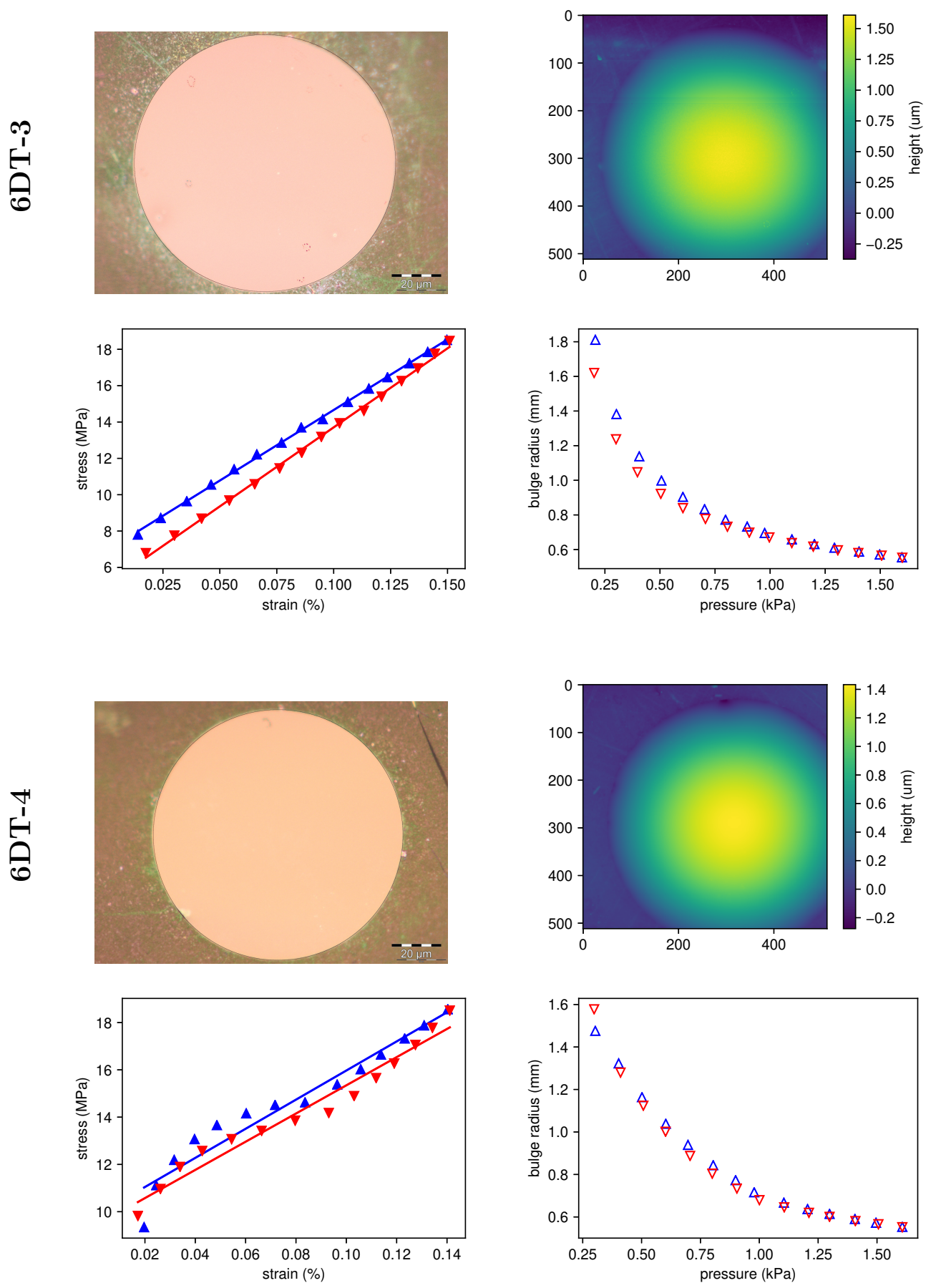


\section{S8.5 8DT Cross-Linked Samples}
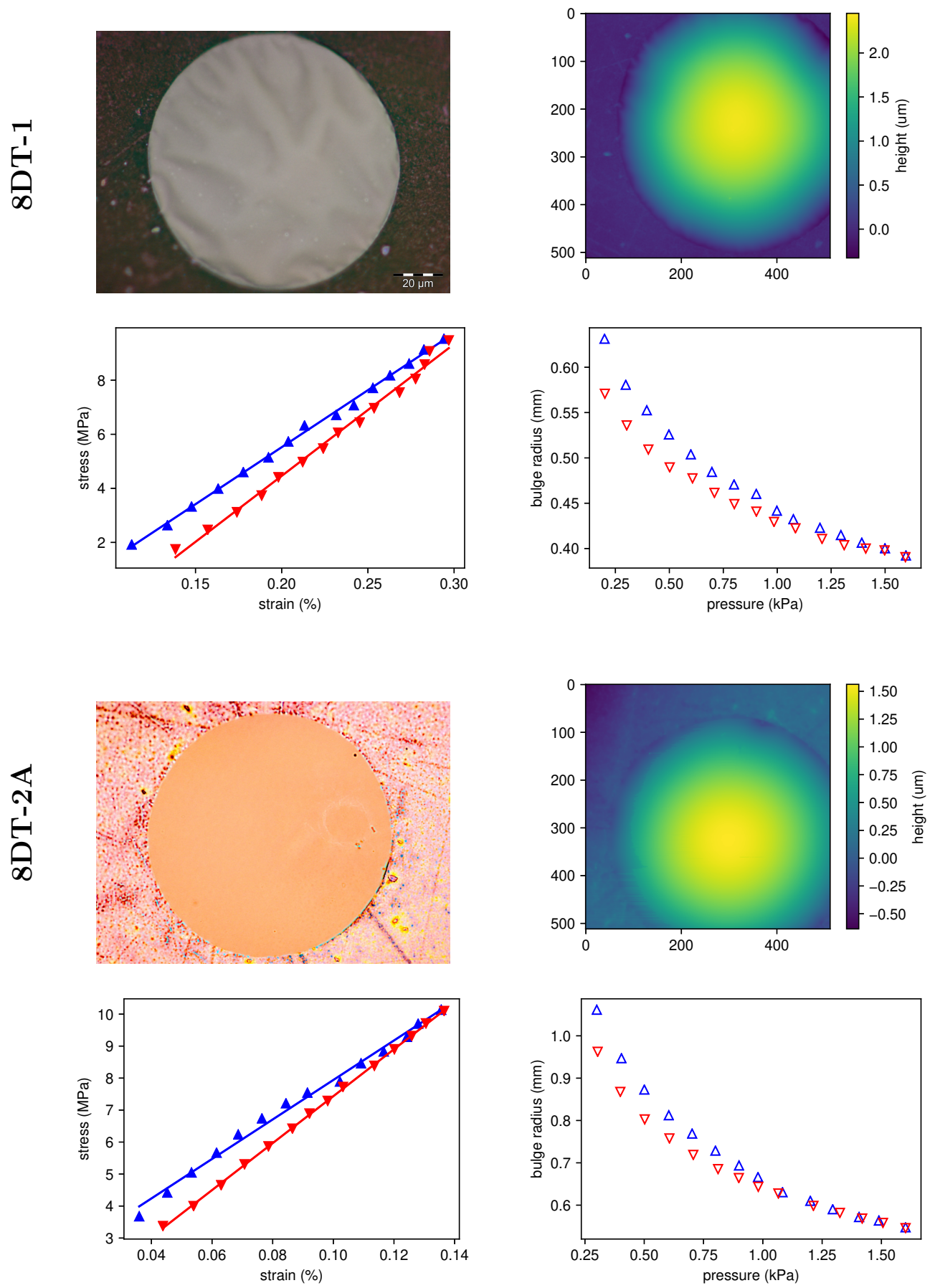

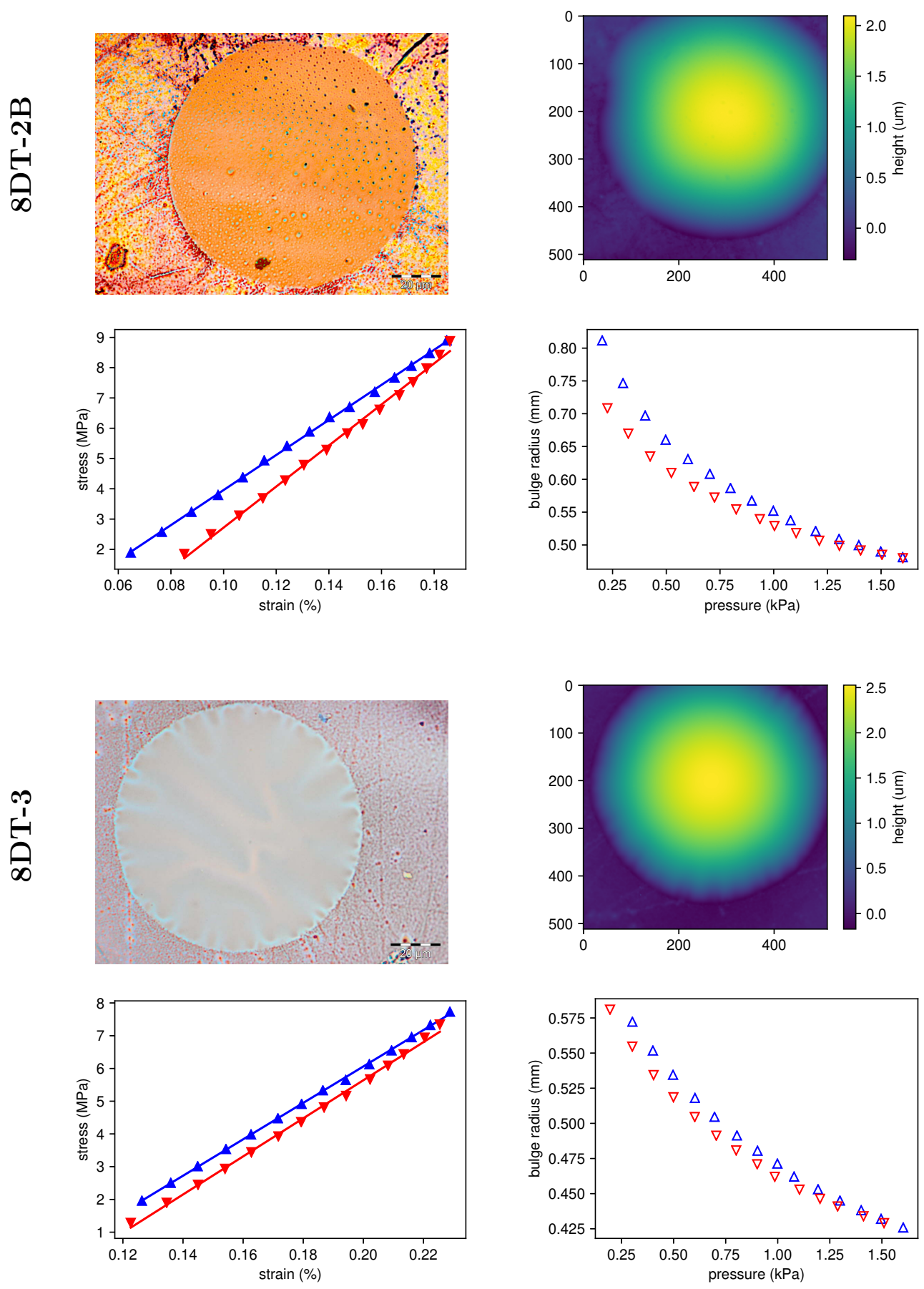

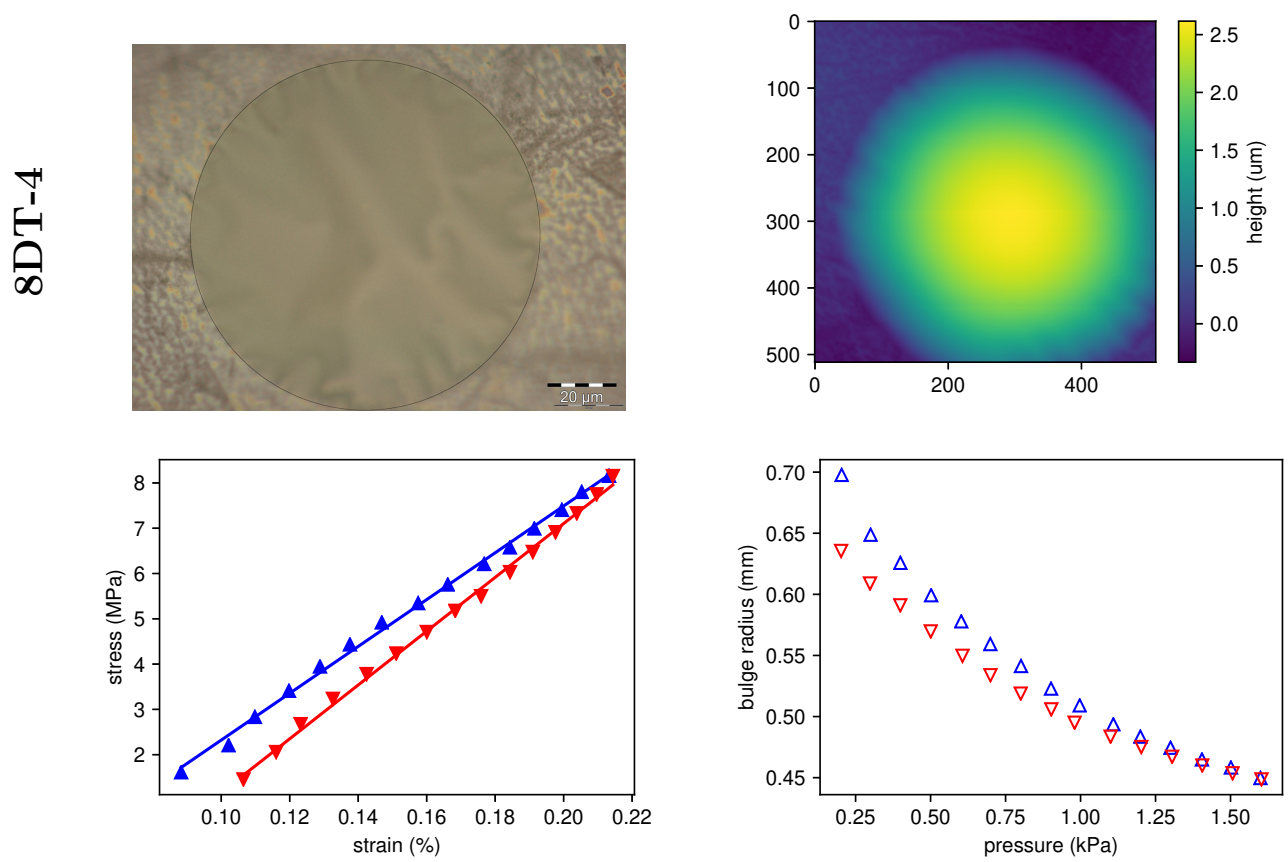


\section{S8.6 9DT Cross-Linked Samples}
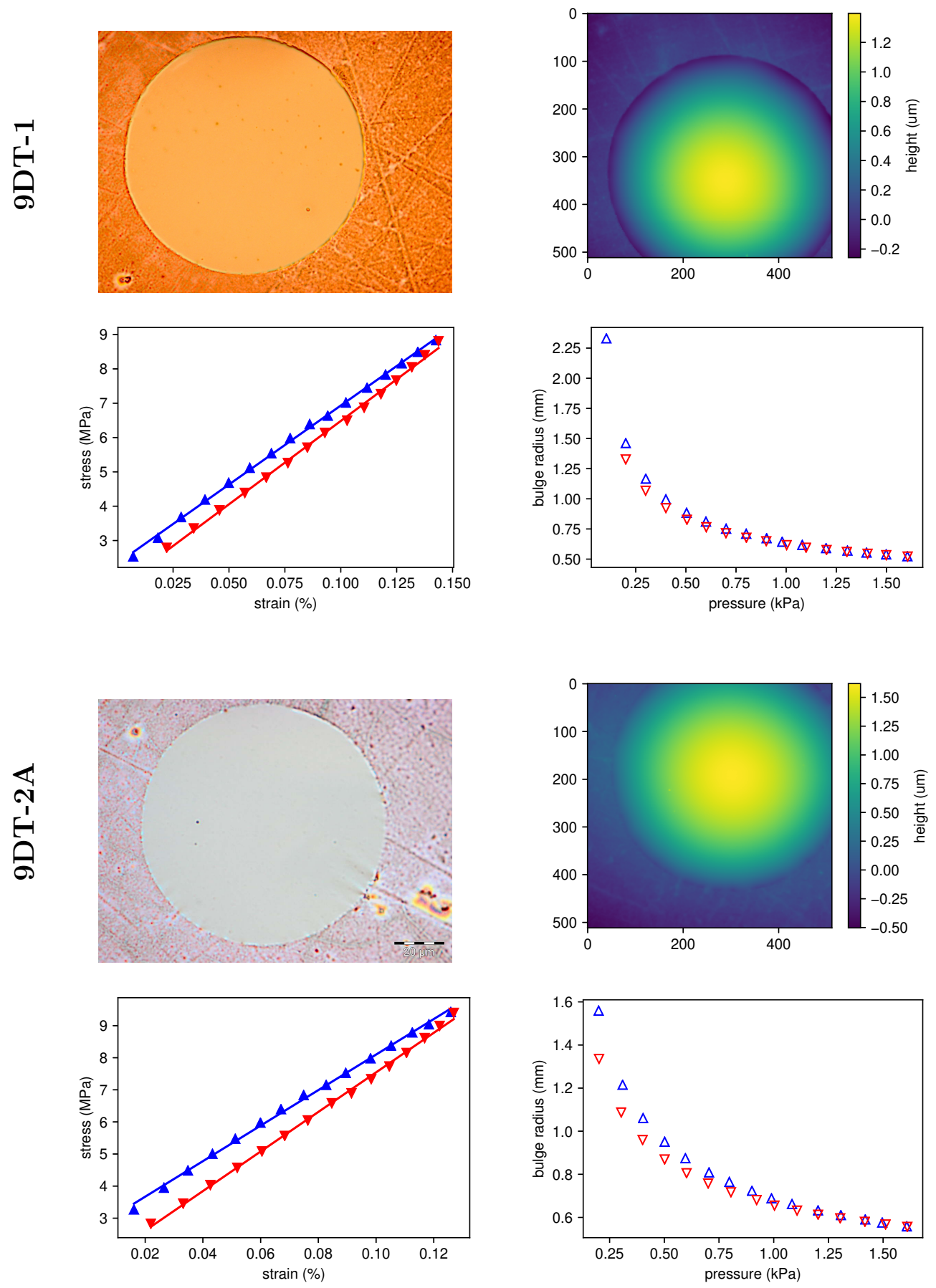

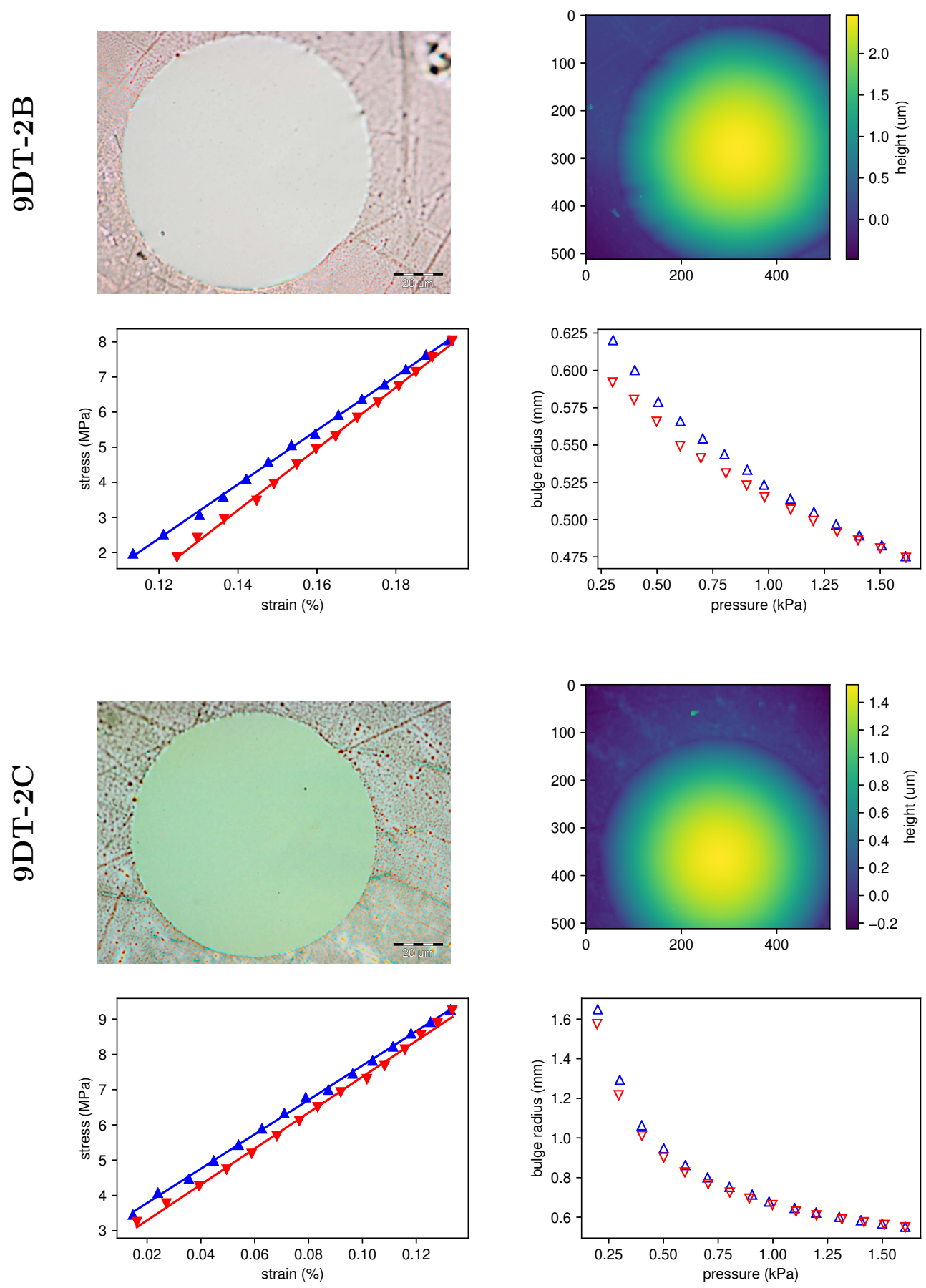

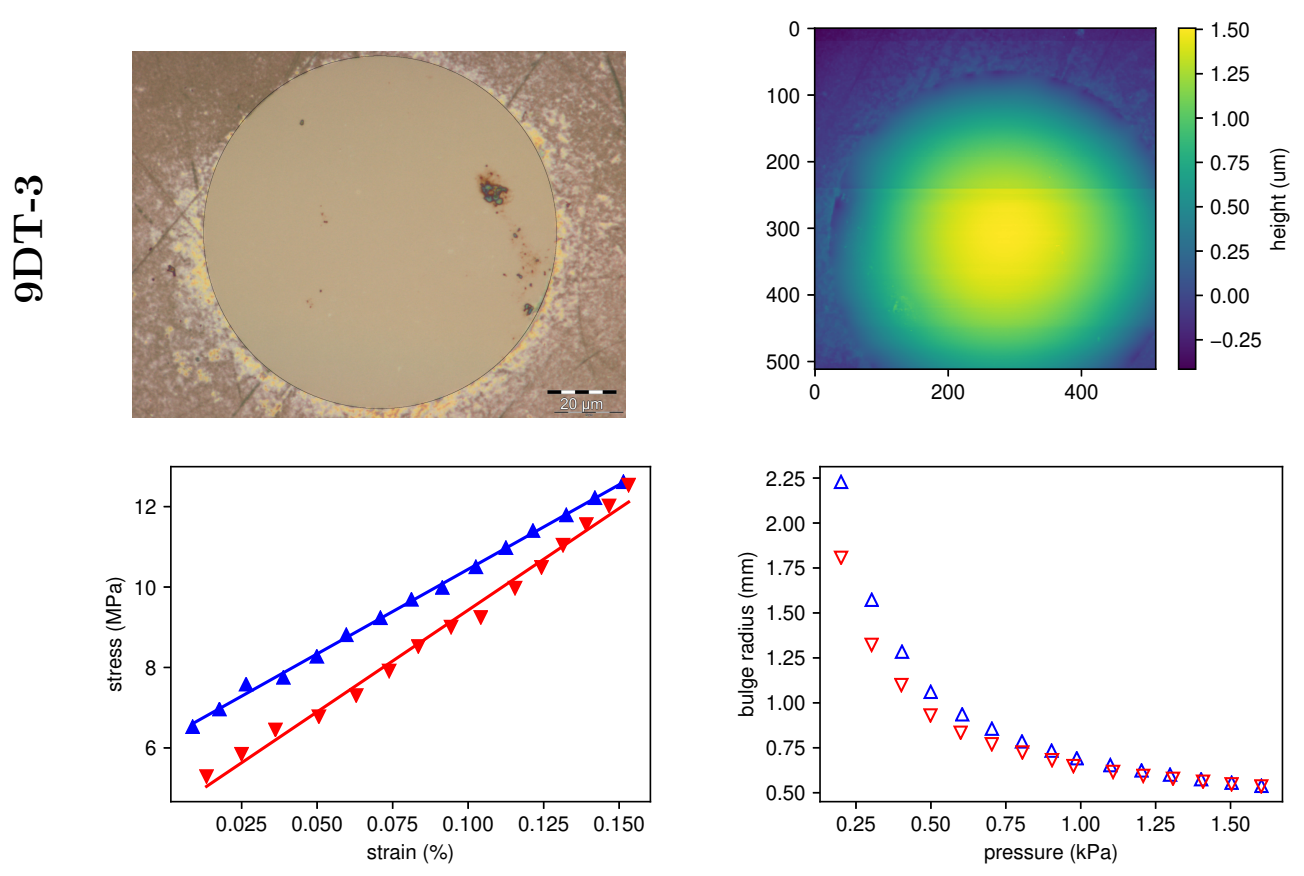


\section{S8.7 10DT Cross-Linked Samples}
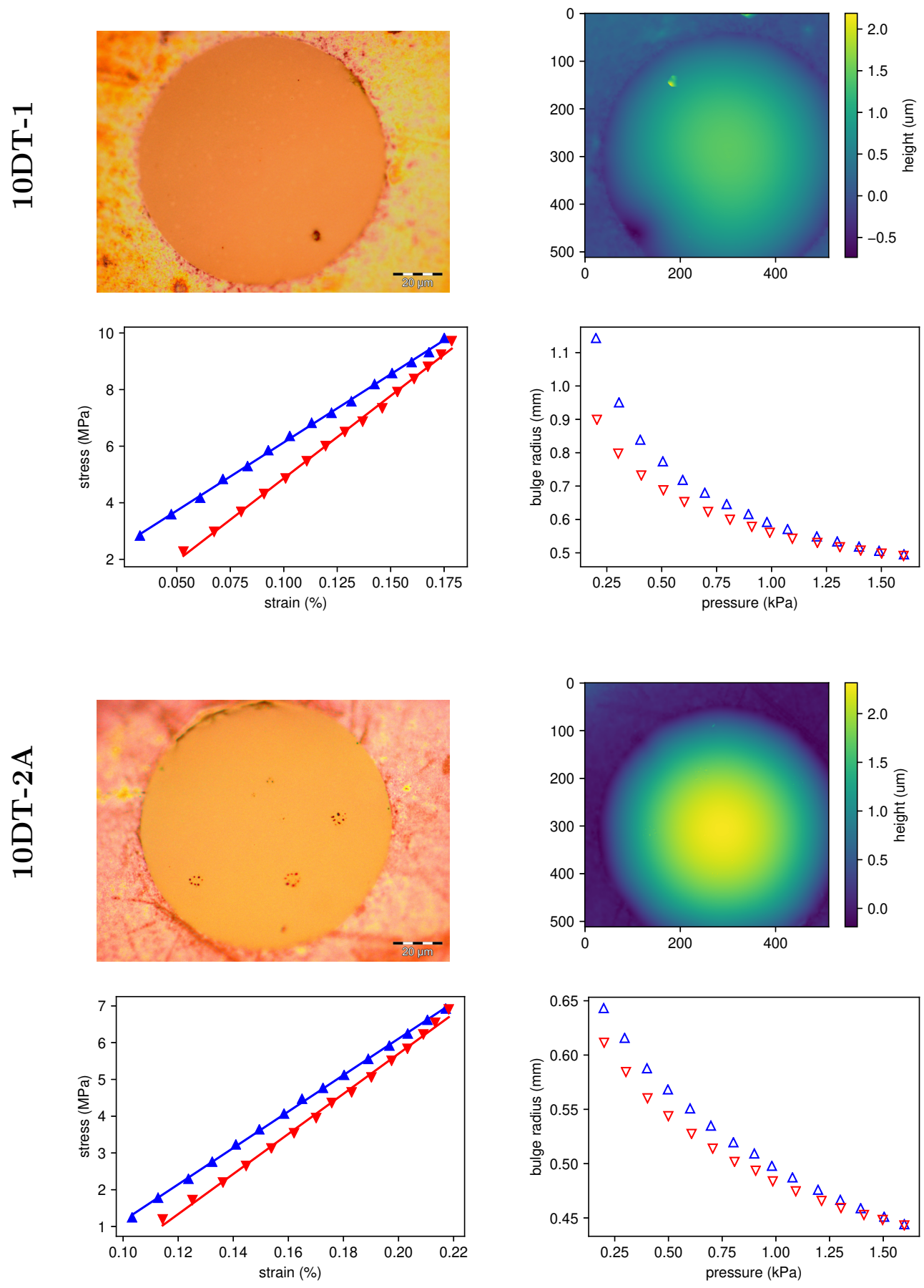

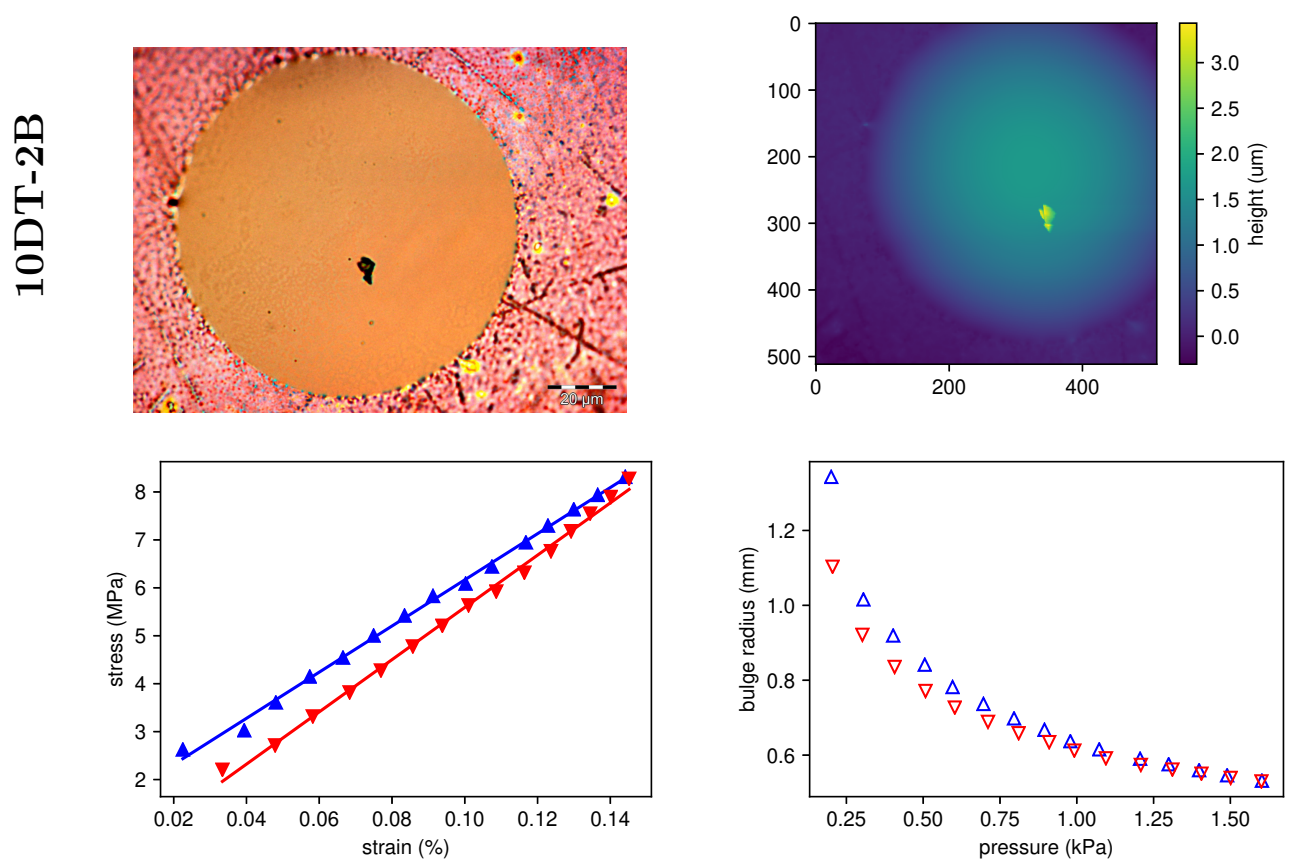

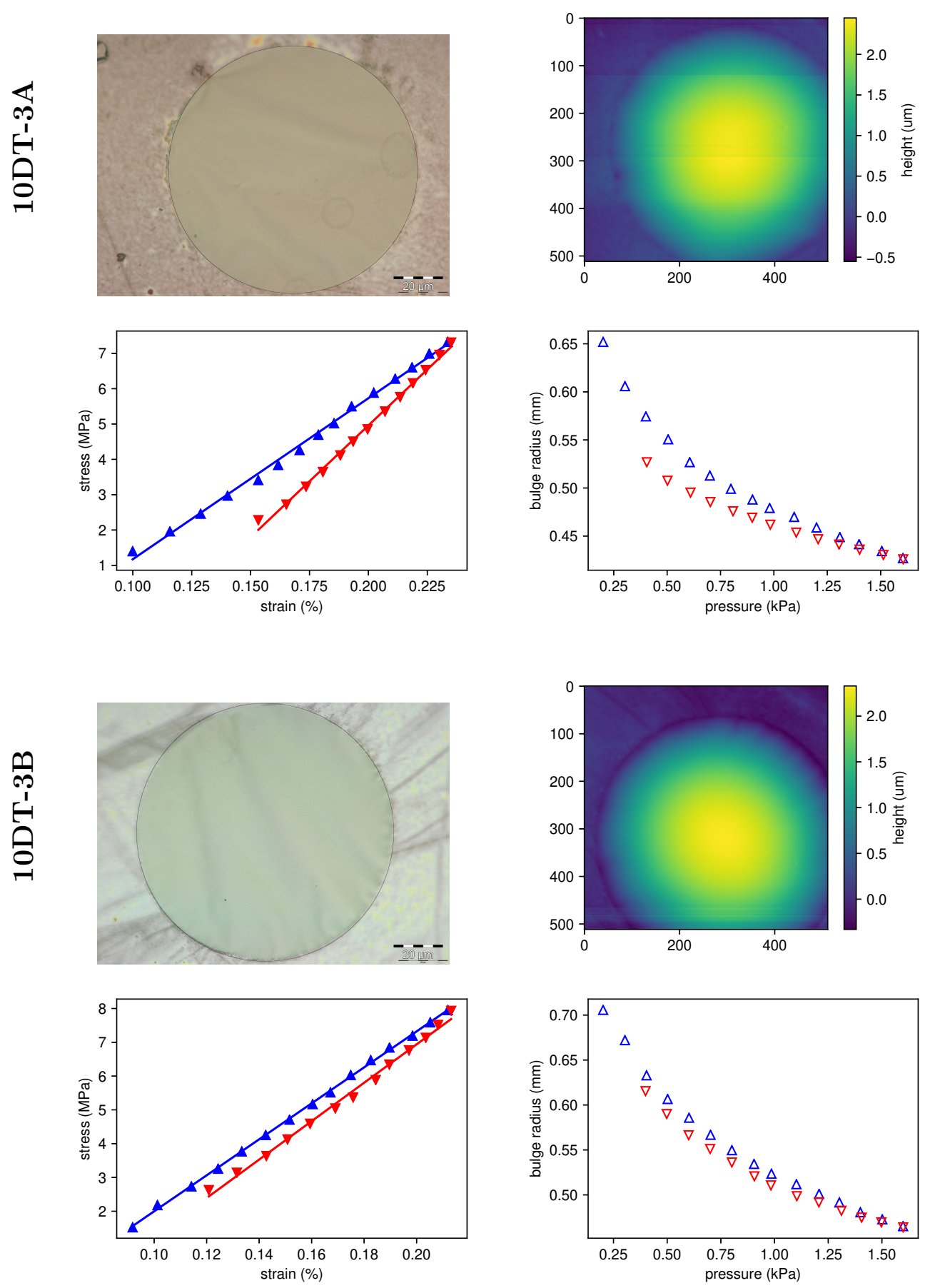

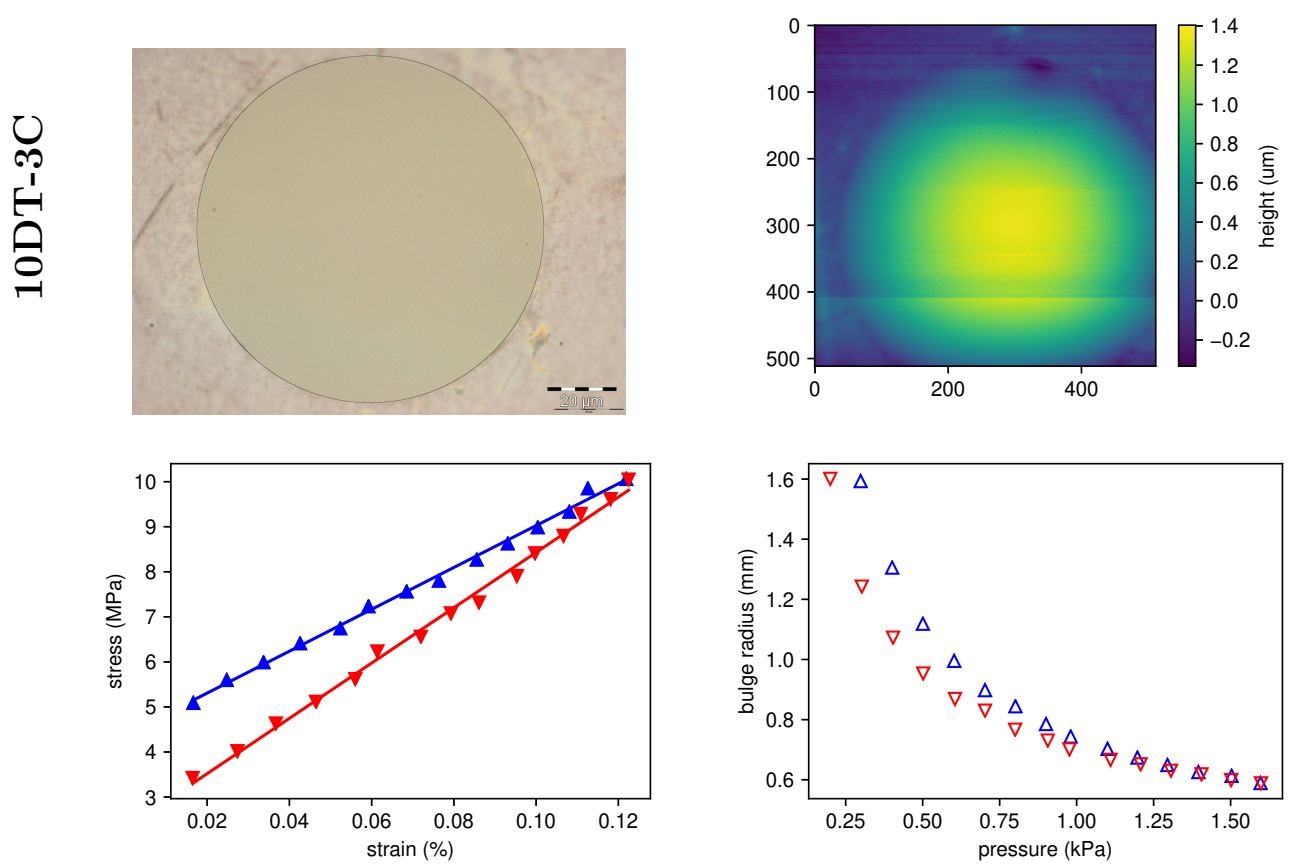


\section{S8.8 BDT Cross-Linked Samples}
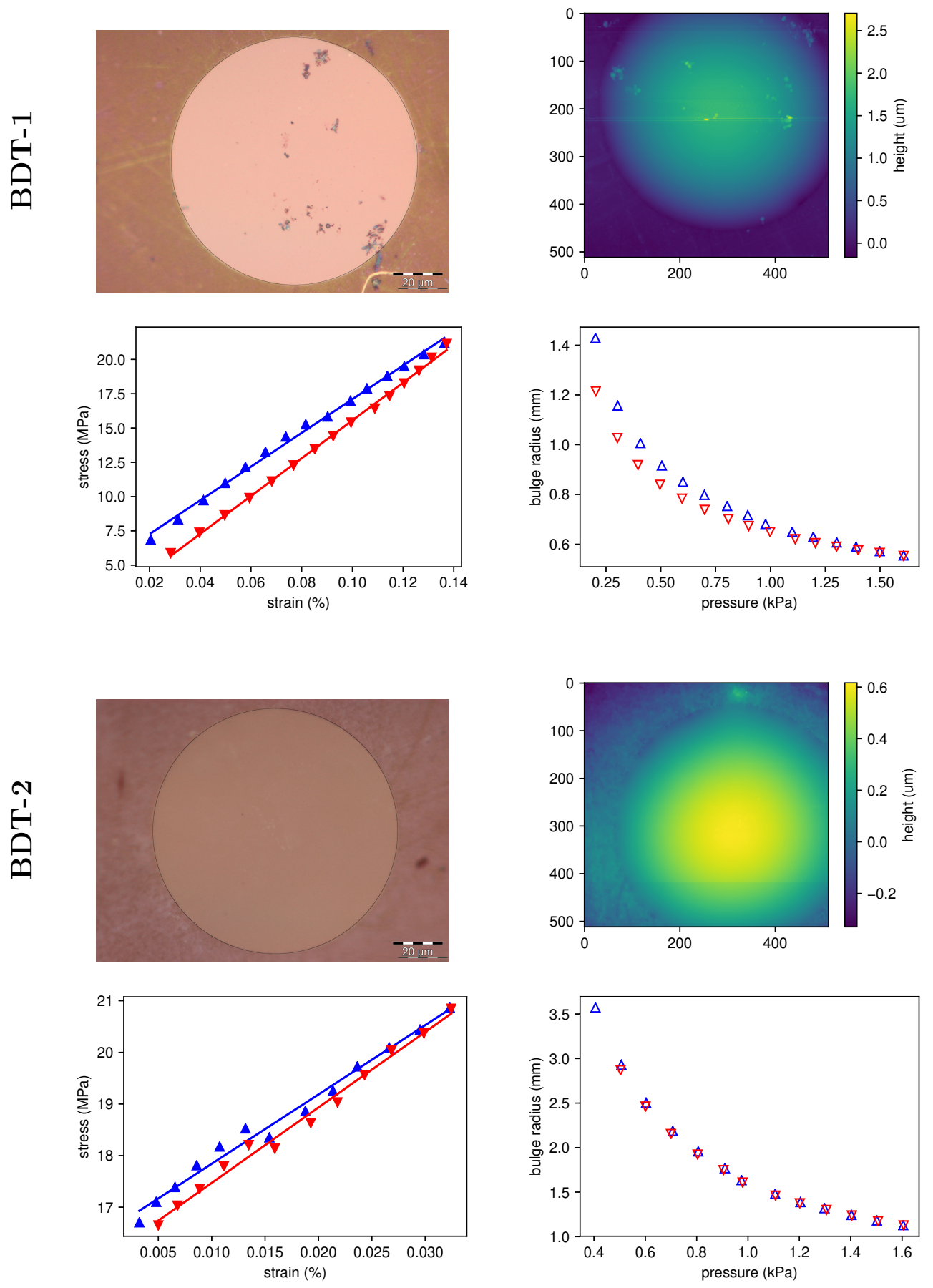


\section{References}

(1) Leff, D. V.; Brandt, L.; Heath, J. R. Synthesis and Characterization of Hydrophobic, Organically-Soluble Gold Nanocrystals Functionalized with Primary Amines. Langmuir 1996, 12, 4723-4730.

(2) Schlicke, H.; Schröder, J. H.; Trebbin, M.; Petrov, A.; Ijeh, M.; Weller, H.; Vossmeyer, T. Freestanding Films of Crosslinked Gold Nanoparticles Prepared via Layer-by-Layer SpinCoating. Nanotechnology 2011, 22, 305303.

(3) Terrill, R. H.; Postlethwaite, T. A.; Chen, C.-h.; Poon, C.-D.; Terzis, A.; Chen, A.; Hutchison, J. E.; Clark, M. R.; Wignall, G.; Londono, J. D. et al. Monolayers in Three Dimensions: NMR, SAXS, Thermal, and Electron Hopping Studies of Alkanethiol Stabilized Gold Clusters. J. Am. Chem. Soc. 1995, 117, 12537-12548.

(4) Förster, S.; Apostol, L.; Bras, W. Scatter: Software for the Analysis of Nano- and Mesoscale Small-Angle Scattering. J. Appl. Cryst. 2010, 43, 639-646. 